Review

\title{
Bismuth Sodium Titanate Based Materials for Piezoelectric Actuators
}

\author{
Klaus Reichmann ${ }^{1, *}$, Antonio Feteira ${ }^{2,+}$ and Ming $\mathrm{Li}^{3,+}$ \\ Received: 19 October 2015; Accepted: 23 November 2015; Published: 4 December 2015 \\ Academic Editor: Lorean Pardo \\ 1 Institute of Chemistry and Technology of Materials, Graz University of Technology, Stremayrgasse 9, \\ Graz 8010, Austria \\ 2 Materials and Engineering Research Institute, Sheffield Hallam University, City Campus, Howard Street, \\ Sheffield S1 1WB, UK; A.Feteira@shu.ac.uk \\ 3 Advanced Materials Research Group, Department of Mechanical, Materials and Manufacturing \\ Engineering, The University of Nottingham, University Park, Nottingham NG7 2RD, UK; \\ Ming.Li@nottingham.ac.uk \\ * Correspondence: k.reichmann@tugraz.at; Tel.: +43-316-8733-2321 \\ + These authors contributed equally to this work.
}

\begin{abstract}
The ban of lead in many electronic products and the expectation that, sooner or later, this ban will include the currently exempt piezoelectric ceramics based on Lead-Zirconate-Titanate has motivated many research groups to look for lead-free substitutes. After a short overview on different classes of lead-free piezoelectric ceramics with large strain, this review will focus on Bismuth-Sodium-Titanate and its solid solutions. These compounds exhibit extraordinarily high strain, due to a field induced phase transition, which makes them attractive for actuator applications. The structural features of these materials and the origin of the field-induced strain will be revised. Technologies for texturing, which increases the useable strain, will be introduced. Finally, the features that are relevant for the application of these materials in a multilayer design will be summarized.
\end{abstract}

Keywords: piezoelectric actuator; multilayer; lead-free; bismuth sodium titanate

\section{Introduction}

Environmental regulations succeeded in replacing lead and lead components in a number of applications like paints, solder and a variety of electronic components. Exempt from this ban of lead are applications and technologies where no proper replacement is available, such as piezoelectric ceramics. These exemptions are limited in time and need to be discussed and renewed periodically. Concerning piezoelectric materials with its "workhorse" Lead-Zirconate-Titanate (PZT), this legal demand has triggered research efforts and materials development for some twenty years. A number of lead-free materials, supported by innovative processing technologies, like texturing, are competitive to replace this well establish compound. The discovery of an extraordinarily large strain generated by field-induced phase transition in Bismuth-Sodium-Titanate based solid solutions draw the attention of researchers to this material system, which seems to be an alternative to PZT for actuator applications. Actuators can be found in a variety of designs; the most common are bending actuators and stack actuators. Most of these ceramic devices are manufactured using multilayer technology, where ceramic layers are cofired with metal layers acting as inner electrodes. With this technology, it is possible to reduce the thickness of the ceramic layers to well below $100 \mu \mathrm{m}$, which enables generating a high electric field with a relatively low voltage applied. Combining this with a large number of layers, a high strain of the actuator can be achieved. A good example of a 
high-performance piezoelectric multilayer device is the stacked actuator for opening diesel injection valves in diesel engines, which consists of more than 300 single layers and has to cope with severe operating conditions (wide temperature range, high mechanical stress, large electric fields) as well as a high demand on reliability and lifetime. Therefore materials development needs to consider a lot more materials properties and issues than just the piezoelectric response.

Talking about lead-free ferroelectrics or piezoelectrics, respectively, with large strain, one may consider four distinct material classes, as presented in the review paper on lead-free piezoelectric ceramics by Rödel, et al. [1]. The first is based on $\mathrm{BaTiO}_{3}$ (BT). Solid solutions with $\mathrm{CaTiO}_{3}$ and $\mathrm{BaZrO}_{3}$, commonly denoted as BCZT [2-6], achieve extraordinarily high strain (exceeding that of PZT) in a temperature range around room temperature. The limiting Curie Temperature $\left(T_{C}\right)$ is approximately $100{ }^{\circ} \mathrm{C}$. The second class, based on $\mathrm{K}_{0.5} \mathrm{Na}_{0.5} \mathrm{NbO}_{3}(\mathrm{KNN})$, exhibits lower strain but the Curie Temperature may reach $450{ }^{\circ} \mathrm{C}$, which is beyond that of PZT-based compounds [1,7-10]. The third group are ferroelectrics based on $\mathrm{Bi}_{0.5} \mathrm{Na}_{0.5} \mathrm{TiO}_{3}$ (BNT) [11-14], where the limiting temperature is not a more or less diffuse Curie Temperature, but a so-called Depolarization Temperature $\left(T_{d}\right)$, whose maximum is around $290^{\circ} \mathrm{C}$ and most doping agents lower that $T_{\mathrm{d}}$. The fourth class comprises so-called BNT-based incipient piezoelectrics [15-21]. In such materials, e.g., the solid solution of BNT and $\mathrm{SrTiO}_{3}$ [15], one can gain giant strains, which are caused by a reversible phase transition from an ergodic relaxor state to a ferroelectric state induced by the electric field applied. This is the class of materials that will be found in most examples given later.

Looking back, it might be justified to say that the greatest push and encouragement for materials scientists in that field came from the publication of Saito, et al. [22] in 2004 and by the two papers from Zhang, et al. [18,19] in 2008. Saitos publications showed that the inferior piezoelectric properties of KNN compared to PZT can be raised to the level of PZT by applying a technology that provides a highly textured ceramics. Therefore, the effect of texturing will be considered in its own section in this paper. Zhang's findings of a field induced giant strain in BNT-BT-KNN and its temperature dependence encouraged other researchers to regard the Depolarization Temperature in that system not as a limit but just as a border to a new "land of hope", where new materials for lead-free piezoelectric actuators can be found.

This contribution will give a short overview of lead-free piezoelectric ceramics with large strain and will introduce the Bismuth-Sodium-Titanate compound and some of its derivatives summarizing their structural peculiarities and the current opinion on the origin of the large field-induced strain. Furthermore, this review will add aspects of the processing technology of texturing, which is able to increase usable strain of these materials and, even more important for energy conversion, coupling factor. In the following sections, the features of a piezoelectric actuator material are outlined, such as blocking force, temperature dependence of strain, and interaction with electrode materials during co-firing, that have to be considered for a useful and reliable device. Examples of material systems used for multilayer actuators, which are described in literature, are provided.

\section{Structure of BNT and Its Solid Solutions}

\subsection{Room Temperature Structure}

The interesting ferroelectric and piezoelectric properties of BNT have triggered extensive studies on its complex perovskite-based crystal structure using a wide range of experimental techniques and simulations. However, to date both the space group at room temperature (RT) and the nature of high temperature phase transitions are still under debate.

The early studies in the 1960s using X-ray diffraction (XRD) suggest BNT adopts either pseudo-cubic [23,24] or rhombohedral [25] symmetry. It was proposed in a later XRD study [26] that the space group is $\mathrm{R} 3 \mathrm{~m}$, which is polar but without octahedral tilting $\left(a^{\circ} a^{\circ} a^{\circ}\right.$, according to the Glazer notation [27]). A subsequent neutron diffraction study revealed the presence of superlattice reflections associated with doubling of unit cell, indicating the space group is R3c [28]. The R3c model 
was adopted in another more detailed neutron diffraction study [29]. In the R3c phase, the cations are displaced parallel to [111] $p$ with the $a^{-} a^{-} a^{-}$antiphase rotations of the $\mathrm{TiO}_{6}$ octahedra about the threefold pseudo-cubic axes.

However, there is also experimental evidence that is inconsistent with the R3c symmetry. The temperature dependence of birefringence and opalescence data suggest a lower than rhombohedral symmetry [30]. An X-ray diffuse scattering study suggests Bi could move off the [111] $p$ axis to improve its coordination environment and consequently reduce the local symmetry to be monoclinic [31]. The X-ray absorption fine structure (XAFS) results [32] show very different Bi-O distances from those refined using the neutron diffraction data. XAFS results reveal the shortest $\mathrm{Bi}-\mathrm{O}$ distance to be $\sim 2.2 \AA$, consistent with that observed in most bismuth oxides. However, the refined structure using the neutron diffraction data with the R3c symmetry leads to severely under-bonded Bi coordination environment with shortest $\mathrm{Bi}-\mathrm{O}$ distance being more than $2.5 \AA$. This study suggests the local environment of $\mathrm{Bi}$ is much more distorted than that expected from the average structure. A neutron scattering study shows the rhombohedral phase has incommensurate modulation along the four-fold axis of a tetragonal phase [33], which is presumably caused by local $\mathrm{Na}$ and Bi ordering. More recent $\mathrm{X}$-ray and neutron total scattering experiments and pair distribution function (PDF) analysis $[34,35]$ demonstrate the complex local structure in BNT. There are distinct $\mathrm{Na}$ and Bi cation displacements as well as two different Bi positions [34].

Based on the high-resolution single-crystal XRD data, a monoclinic Cc model was proposed [36]. This model was then adopted in the subsequent high-resolution powder XRD studies $[37,38]$. The Cc phase has very similar lattice parameters [36] $(a=b=3.887, c=3.882, \alpha=\beta=89.944, \gamma=89.646)$ as compared to the R3c phase $(a=b=c=3.885, \alpha=\beta=\gamma=89.83)$ but has a different octahedra tilting system of $a^{-} a^{-} c^{-}$. The tilting is still out-of-phase in the $x, y$, and $z$ directions but the tilting angel is different in the $z$-direction. Figure 1 show the crystal structure of the two models. The R3c model could fit the synchrotron X-ray patterns collected using calcined powders but peak splitting is observed in the sintered samples [37]. The Cc model gives better fit than the R3c model. Nevertheless, it is still not completely satisfactory. It does not resolve the issue of under-bounded Bi environment [36] and could not model small variations in the diffraction patterns associated with local disorder [38]. The monoclinic (Cc) + cubic $(\mathrm{Pm} \overline{3} \mathrm{~m})$ model was employed to fit the XRD patterns for the sintered samples in the previous report [38].
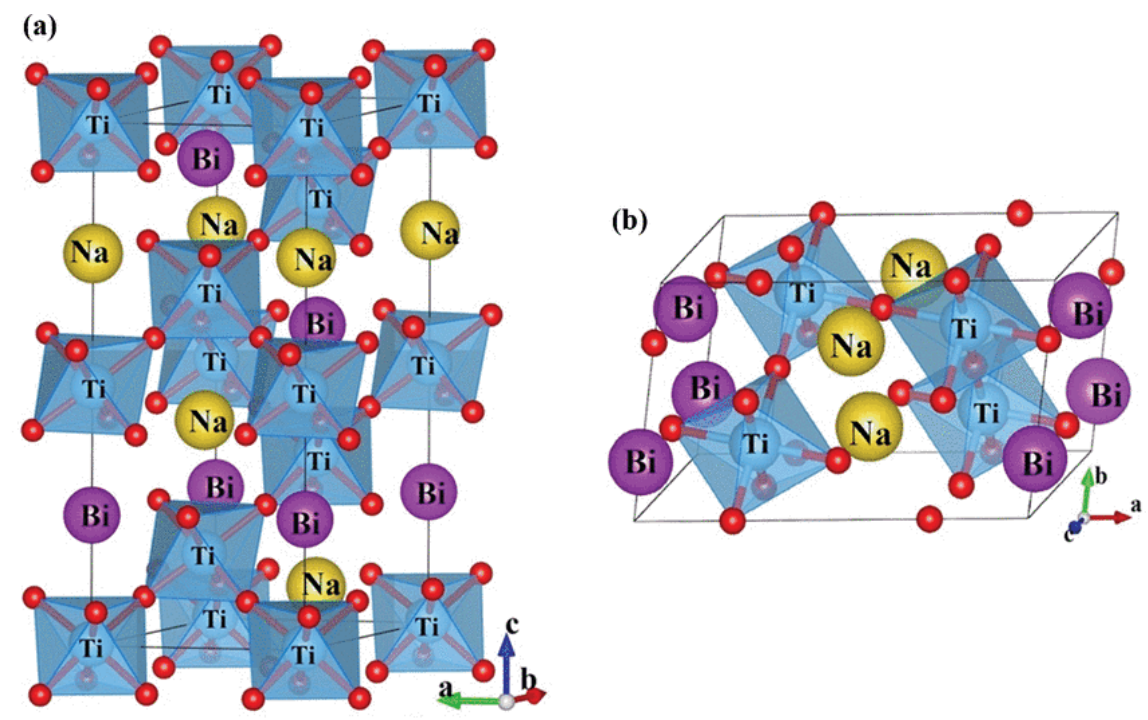

Figure 1. Crystal structure models of (a) rhombohedral R3c (hexagonal setting); and (b) monoclinic Cc phases (from reference [39], Copyright from The American Physical Society 2013). 
Based on a combined study using electron, X-ray, and neutron diffraction coupled with first principles calculation, and the dielectric, ferroelectric, and piezoelectric measurements [39-41], it is proposed that the $\mathrm{Cc}$ and $\mathrm{R} 3 \mathrm{c}$ phases coexist at RT in undoped samples. The relative fraction of the two phases depends on thermal, mechanical, and electrical stimuli. Under external electric field the Cc phase is irreversibly suppressed and the XRD patterns of poled BNT samples could be nicely fitted with the R3c model alone [39-41]. It is therefore concluded that the Cc phase is not a new equilibrium phase. Instead, it is associated with local structural and strain heterogeneities. External electrical filed can remove such heterogeneities and the symmetry becomes purely rhombohedral. A transmission electron microscopy (TEM) work [42] shows defect-free BNT has an average R3c symmetry on length scales of a few nanometers. The bulk BNT contains various types of defects including antiphase boundaries, domain walls, and tetragonal platelets. The Cc phase is present only in the vicinity of domain walls.

TEM work also reveal the presence of nanometer scale tetragonal platelets with $a^{\circ} a^{\circ} c^{+}$tilting system [43,44]. It is proposed BNT consists of two phases with tetragonal $a^{\circ} a^{\circ} c^{+}$platelets inhomogeneously distributed in the $a^{-} a^{-} a^{-}$rhombohedral matrix. A different explanation of the electron diffraction data is that the structure can be best described by a "continuous tilt" model [45]. Nanoscale domains with $a^{-} a^{-} c^{+}$tilting are limited to a length of a few unit cells and assemblages of such nanodomains exhibit an average $a^{-} a^{-} c^{-}$tilting system. This continuous tilting model is consistent with the "average" monoclinic structure. The Cc phase is observed in another TEM work [46]. The authors also stressed that, as TEM is a local structure technique, such results do not rule out the existence of other phases.

Apart from the complex cation displacements and oxygen octahedra tilting, possible $\mathrm{Na}$ and $\mathrm{Bi}$ ordering is another factor adding further complexity to the crystal structure. In perovskite oxides, larger difference in charge and size generally leads to cation ordering whereas similar charge and size of cations give disordered structure [47,48]. The ionic radii of $\mathrm{Na}$ are close to that of Bi [49], implying long range ordering is unlikely. The charge difference between $\mathrm{Na}^{+}$and $\mathrm{Bi}^{3+}$ is not large enough to guarantee long range A-site cation ordering. Simulation results [50] suggest the calculated ordering energies are small as compared to the thermal energy and only local ordering is possible. Experimentally there are inconsistent evidences on the A-site cation ordering. X-ray and neutron data reveal no superstructure peaks associated with long range $\mathrm{Na}$ and $\mathrm{Bi}$ ordering [29,35]. In one report [51], however, it is claimed, based on the single crystal XRD data, long range ordering exists but is very weak. Raman spectroscopy data $[52,53]$ support the existence of local $\mathrm{Na} / \mathrm{Bi}$ ordering. However, TEM data [45] show no evidence of local Na/Bi ordering.

\subsection{High Temperature Phase Transitions}

BNT exhibits so-called "peculiar" ferroelectric behaviors. The temperature dependence of relative permittivity $\left(\varepsilon_{r}\right)$ shows a broad maximum at $\sim 320{ }^{\circ} \mathrm{C}\left(T_{\mathrm{m}}\right)$ and a small hump at $\sim 200{ }^{\circ} \mathrm{C}[23,54]$. Linear thermal expansion coefficient also shows noticeable changes at the temperature range of $200-320{ }^{\circ} \mathrm{C}$ [23]. A large hysteresis of $50-60{ }^{\circ} \mathrm{C}$ for various physical properties including dielectric [55], thermal [55] and optical [56] properties is observed at 200-320 ${ }^{\circ} \mathrm{C}$. Extensive efforts have been made to probe the structural origins associated with the temperature dependence of the physical properties $[26,29,38,52,55,57-66]$. The long outstanding puzzle remains that the average structure obtained using X-ray and neutron diffraction $[29,38]$ does not coincide with the physical properties.

It is generally believed that BNT exhibits at least two phase transitions between RT and $520{ }^{\circ} \mathrm{C}[26,29,38,52,55,57-66]$. On cooling, BNT transforms from cubic to tetragonal polymorphism (space group P4bm) at $\sim 520^{\circ} \mathrm{C}$ and to rhombohedral polymorphism at $\sim 250{ }^{\circ} \mathrm{C}$ [29]. Rhombohedral and tetragonal polymorphisms coexist at $\sim 250-400{ }^{\circ} \mathrm{C}[29,63]$. BNT adopts a cubic structure (space group Pm $3 \bar{m}$ ) above $\sim 520{ }^{\circ} \mathrm{C}$. The phase transition at $520{ }^{\circ} \mathrm{C}$ is of first order. Differential scanning calorimetry (DSC) reveals a maximum of specific heat on heating and a minimum on 
cooling [55]. A maximum of linear thermal expansion coefficient is also observed [55]. However, no obvious permittivity anomaly observed at $\sim 520{ }^{\circ} \mathrm{C}$. A recent study [67] reveals a loss peak at $\sim 500{ }^{\circ} \mathrm{C}$ in highly-insulating $\mathrm{Nb}$-doped BNT samples. Undoped BNT samples typically exhibit high leakage current at this temperature range. Therefore the loss peak could be masked by the high loss background and becomes invisible. The loss peak at $\sim 500{ }^{\circ} \mathrm{C}$ could be associated with the cubic-tetragonal phase transition but further study is needed to confirm this.

The most intriguing behavior occurs at $200-320{ }^{\circ} \mathrm{C}$. X-ray and neutron diffraction $[29,38]$ reveal no phase transition at $320{ }^{\circ} \mathrm{C}$ where $\varepsilon_{r}$ exhibits a maximum and at $200{ }^{\circ} \mathrm{C}$ where BNT loses polarization. One early study [57] suggests BNT is antiferroelectric at $200-320{ }^{\circ} \mathrm{C}$. On cooling it exhibits paraelectric-antiferroelectric phase transition at $320^{\circ} \mathrm{C}$ and antiferroelectric-ferroelectric phase transition at $200{ }^{\circ} \mathrm{C}$. Double hysteresis loops, a typical characteristic of antiferroelectrics, are presented as the evidence [57]. However, no superlattice reflection associated with antiparallel cation displacements is observed by X-ray and neutron diffraction and Raman data $[29,38,60]$.

High temperature in-situ TEM studies [68-70] provide an explanation for the ferroelectric behaviors at $200-520{ }^{\circ} \mathrm{C}$. The rhombohedral to tetragonal phase transition upon heating involves two processes and the formation of an intermediate orthorhombic Pnma phase. An intermediate modulated phase consisting of R3c blocks periodically separated by orthorhombic Pnma sheets starts to grow slightly above $200{ }^{\circ} \mathrm{C}$ through a micro twining process. With increasing temperature the volume fraction of orthorhombic Pnma sheets increases. At $\sim 300^{\circ} \mathrm{C}$ the orthorhombic Pnma phase forms that then transforms into the tetragonal polymorphism $(\mathrm{P} 4 / \mathrm{mbm})$ at $320{ }^{\circ} \mathrm{C}$. Note that the orthorhombic phase has not been observed by X-ray/neutron diffraction studies. The possible routes of high temperature phase transitions based on TEM and X-ray/neutron diffraction are summarized in Figure 2 [29,68,69].

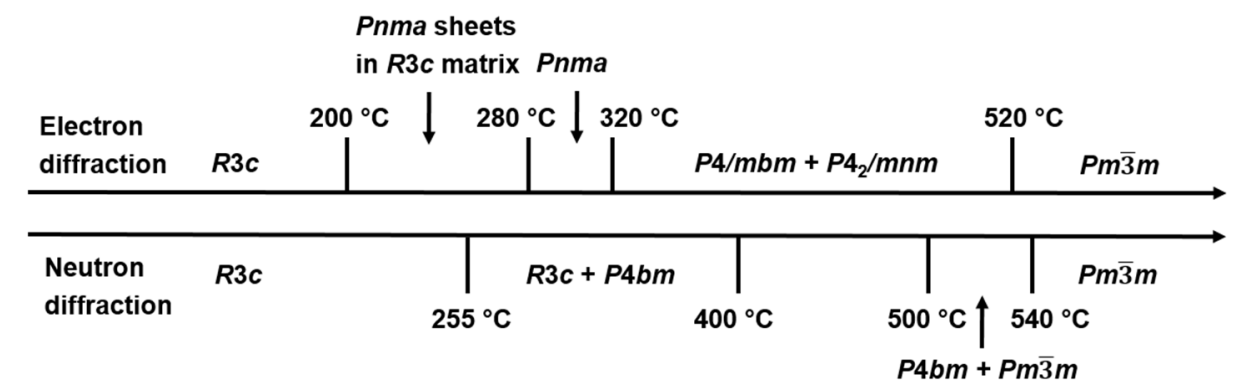

Figure 2. Reported possible phase transition routes based on TEM and X-ray/neutron diffraction studies (data from references $[29,68,69])$.

In summary, BNT exhibit extremely complex crystal structure caused by distinctly different displacement of $\mathrm{Na}$ and Bi ions, complex octahedral tilting, possible local A-site cation ordering as well as local deviations from global structure due to various defects that are sensitive to external stimuli. In addition, the deviations from cubic structure are small [36]. For example, the RT rhombohedral angle is $89.83^{\circ}$, very close to $90^{\circ}$. For the tetragonal phase, c/a is 1.004 . All these factors, especially when combined together, make it tremendously challenging to reveal the true symmetry of BNT.

\subsection{Phase Diagrams of Solid Solutions}

Piezoelectric materials exhibit enhanced properties with compositions around the so-called morphotropic phase boundary (MPB) regions [71]. For the well-known binary phase $\mathrm{PbZr}_{1-x} \mathrm{Ti}_{x} \mathrm{O}_{3}$ (PZT) system, the MPB lies at $x=0.48$. For $x<0.48$, PZT adopts the rhombohedral R3c symmetry. For $x>0.48$, PZT adopts tetragonal P4mm symmetry. For BNT, various solid solutions with other ferroelectric materials including $\mathrm{BaTiO}_{3}(\mathrm{BT}), \mathrm{Bi}_{1 / 2} \mathrm{~K}_{1 / 2} \mathrm{TiO}_{3}(\mathrm{BKT})$ and $\mathrm{K}_{1 / 2} \mathrm{Na}_{1 / 2} \mathrm{NbO}_{3}(\mathrm{KNN})$ have been developed to obtain MPBs for better piezoelectric properties [16,72-89]. The approach is to 
combine the rhombohedral BNT with some tetragonal compounds (e.g., BT, BKT) to create MPB compositions (similar to the case of PZT). Addition of other components just increases the diffuseness of phase transitions.

The phase diagram of the binary system $(1-x) \mathrm{Bi}_{1 / 2} \mathrm{Na}_{1 / 2} \mathrm{TiO}_{3}-x \mathrm{BaTiO}_{3}(\mathrm{BNT}-\mathrm{BT})$, Figure $3 \mathrm{a}$, reveals the presence of an $\mathrm{MPB}$ between ferroelectric rhombohedral and tetragonal phases at $x$ close to $0.06-0.08$ [72]. The existence of MPB at this composition appears evident based on enhanced piezoelectric properties. The exact structure at MPB is however still under debate [80-83]. The predicted MBP using ab initio calculations lies at $x=0.35$ [90], very different from the experimental values, which is presumably caused by temperature effects associated with 0 kelvin approximation of the calculation and uncertainty in the experimental data [90]. Another MPB at $x=0.03-0.04$ was recently found [46], which separates the monoclinic Cc and rhombohedral R3c phases. It was also reported that electrical poling can create, destroy, or even replace the MPB with another one in BNT-BT [91].

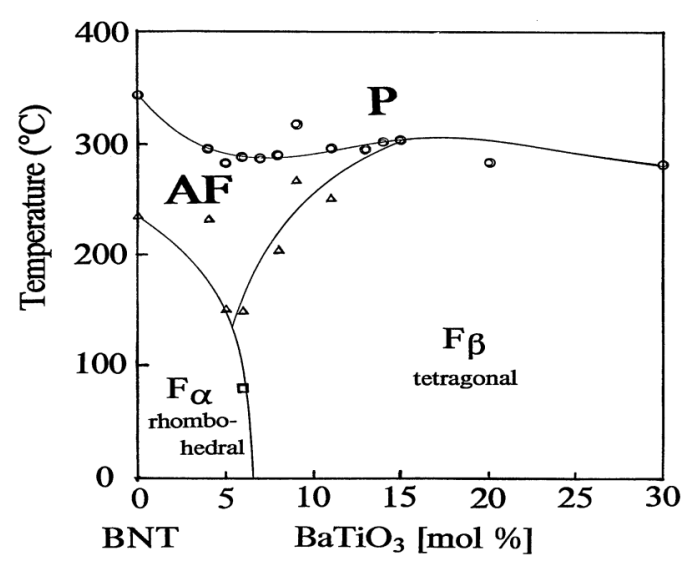

Figure 3. Morphotropic phase boundary in BNT-based solid solutions with $\mathrm{BaTiO}_{3}$, for poled ceramics ([72], Copyright from The Japan Society of Applied Physics 1991).

There have been inconsistent reports on the MPB in the $(1-x) \mathrm{Bi}_{1 / 2} \mathrm{Na}_{1 / 2} \mathrm{TiO}_{3}-x \mathrm{Bi}_{1 / 2} \mathrm{~K}_{1 / 2} \mathrm{TiO}_{3}$ system (BNT-BKT). MPB lies at $x$ close to 0.16-0.20 [73]. Broader composition range $(x=0.08-0.3)$ was also reported [92]. There are also reports claiming no coexistence of rhombohedral/tetragonal phases in BNT-BKT single crystals [93,94]. It is noted the final compositions, as analyzed using X-ray fluorescence (XRF) and inductively coupled plasma-optical emission spectroscopy (ICP-OES), show clearly a much lower potassium content than the nominal values. The final compositions are different in the two reports $[93,94]$, suggesting sample processing conditions may significantly influence the final compositions. This may explain the reported discrepancies in the literature.

The ternary system BNT-BT-KNN (ratio: 92/6/2) exhibits giant strain [77]. The optimised BNT-BT-BKT (ratio: 85.2/2.8/12) system combines a relative high Curie temperature and high piezoelectric constant [88].

\subsection{Nonstoichiometry and Defect Chemistry}

Small compositional deviations of either A-site cations or Ti cation have been shown to influence the crystal structure, ceramic microstructure and piezoelectric properties [51,54,95-101]. Either Na deficiency or Bi excess in the nominal starting composition enhances the dc resistivity, $\mathrm{d}_{33}$ but lowers $T_{\mathrm{d}}$, octahedral tilt angle and ceramic grain size [54,96-98]. On the other hand, either Na excess or Bi deficiency lowers the RT dc resistivity, $\mathrm{d}_{33}$ but enhances $T_{\mathrm{d}}$, octahedral tilt angle and ceramic grain size [54,96-98]. Figure 4 shows the variations of $d_{33}, T_{d}$, relative permittivity and loss tangent with $\mathrm{Na}$ and Bi stoichiometry. 
It is also noted that the dielectric loss of compositions with $\mathrm{Na}$ deficiency or Bi excess is very low $(<0.01)$ at $300-500^{\circ} \mathrm{C}$, whereas the dielectric loss of compositions with $\mathrm{Na}$ excess or Bi deficiency increases sharply from $\sim 200{ }^{\circ} \mathrm{C}$. The changes of RT dc resistivity and the dielectric loss imply the A-site cation nonstoichiometry changes bulk electrical conductivity.
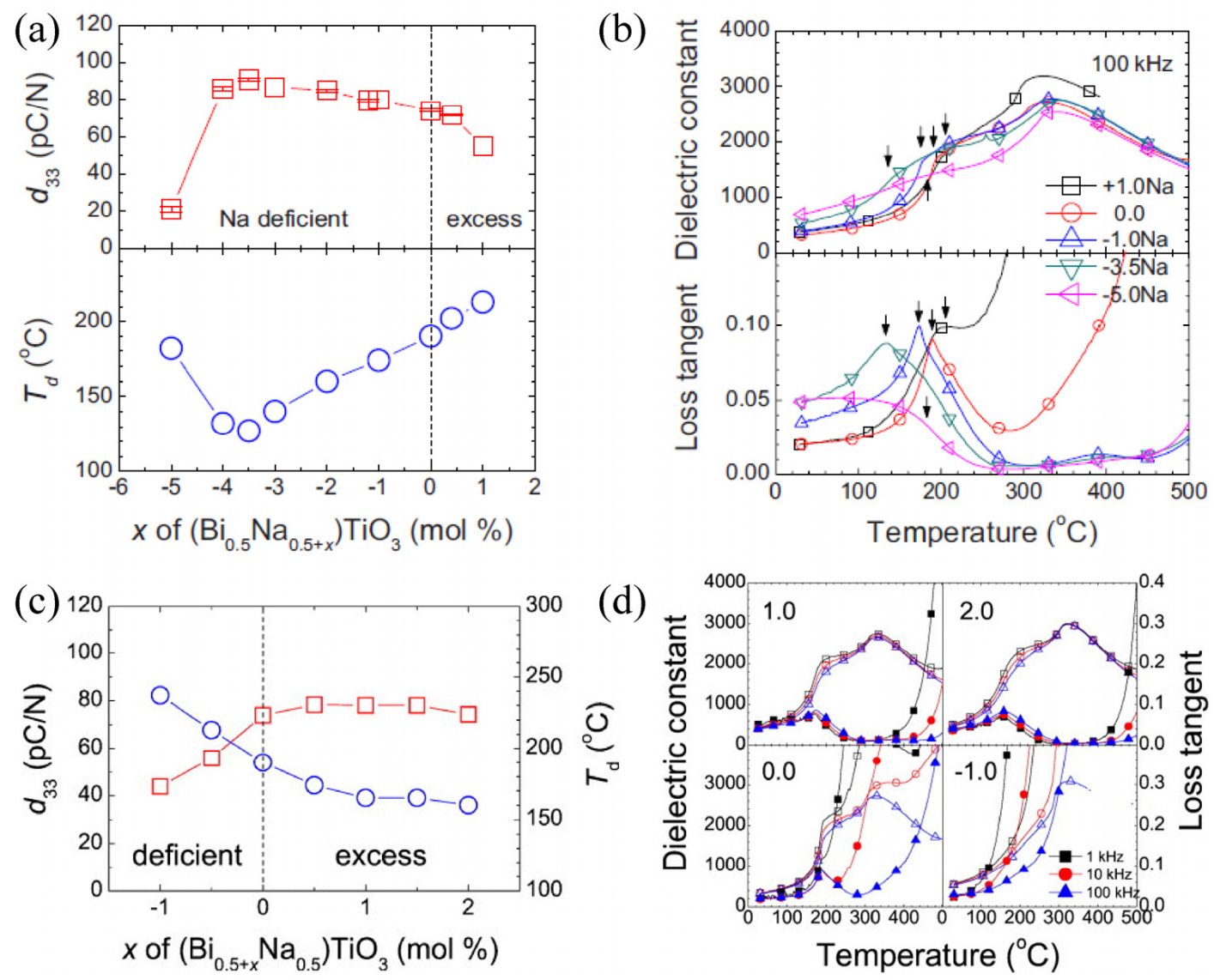

Figure 4. Influence of $(\mathbf{a}, \mathbf{b}) \mathrm{Na}$ and $(\mathbf{c}, \mathbf{d})$ Bi nonstoichiometry on depolarization temperature $\left(T_{\mathrm{d}}\right), \mathrm{d}_{33}$, relative permittivity and loss tangent (Reprinted with permission from references [96,97] Copyright from American Institute of Physics 2010, 2011).

The electrical conduction mechanisms in BNT were recently clarified using a combination of impedance spectroscopy, electromotive force and ${ }^{18} \mathrm{O}$ tracer diffusion measurements [102,103]. BNT shows very different electrical behavior as compared to other titanates such as $(\mathrm{BaSr}) \mathrm{TiO}_{3}$ in that BNT exhibit high oxide ion conductivity (depending on $\mathrm{Na} / \mathrm{Bi}$ stoichiometry) whereas conductivity in $(\mathrm{BaSr}) \mathrm{TiO}_{3}$ is dominated by electronic conduction. It is well known that low levels of nonstoichiometry $(<1$ at \%) could lead to significant changes of electronic conductivity in $(\mathrm{BaSr}) \mathrm{TiO}_{3}$ [104]. The nonstoichiometry may be associated with deliberate chemical doping, unintentional element loss/gain during sample processing and impurities. Small compositional variations also induce significant changes in the electrical conductivity in BNT, which however has a different origin and is related to a switch between electronic conduction and oxygen ion conduction [102,103].

The Arrhenius-type plots of bulk conductivity (Figure 5) show the BNT-based samples with slightly different starting compositions can be divided into two groups [102,103]. Nominal compositions with $\mathrm{Bi}$ excess $\left(\mathrm{Bi}_{0.51} \mathrm{NT}\right)$ or Na deficiency $\left(\mathrm{BNa}_{0.49} \mathrm{~T}\right)$ exhibit low conductivity with an activation energy $\left(E_{\mathrm{a}}\right)$ for bulk conduction of $\sim 1.7 \mathrm{eV}$. The reported optical band gap $\left(E_{\mathrm{g}}\right)$ for BNT is in the range of 3.0-3.5 eV [105-107], suggesting the electrical conduction is close to/dominated 
by intrinsic electronic conduction where $E_{\mathrm{g}} \sim 2 E_{\mathrm{a}}$. The nominally stoichiometric BNT and the compositions with Bi deficiency or $\mathrm{Na}$ excess exhibit much higher conductivity (by more than three orders of magnitude at temperatures below $600{ }^{\circ} \mathrm{C}$ ). The $E_{\mathrm{a}}$ decreases to $0.8-0.9 \mathrm{eV}$ and $\sim 0.4-0.5 \mathrm{eV}$ for the temperature ranges below and above the temperature associated with the maximum in $\varepsilon_{r}$ $\left(T_{\mathrm{m}} \sim 320^{\circ} \mathrm{C}\right)$, suggesting a change in electrical conduction mechanism. A combination of impedance spectroscopy, electromotive force (EMF) and ${ }^{18} \mathrm{O}$ tracer diffusion measurements confirm the higher conductivity is associated with oxygen ion conduction [102,103]. The high oxygen ion conductivity is attributed to high oxygen ion mobility associated with highly polarized $\mathrm{Bi}^{3+}$ cations and weak $\mathrm{Bi}-\mathrm{O}$ bond [108] as well as oxygen vacancies generated together with bismuth vacancies:

$$
2 \mathrm{Bi}_{\mathrm{Bi}}^{\times}+3 \mathrm{O}_{\mathrm{O}}^{\times} \rightarrow 2 \mathrm{~V}_{\mathrm{Bi}}^{\prime \prime \prime}+3 \mathrm{~V}_{\mathrm{O}}^{\bullet \bullet}+\mathrm{Bi}_{2} \mathrm{O}_{3}
$$

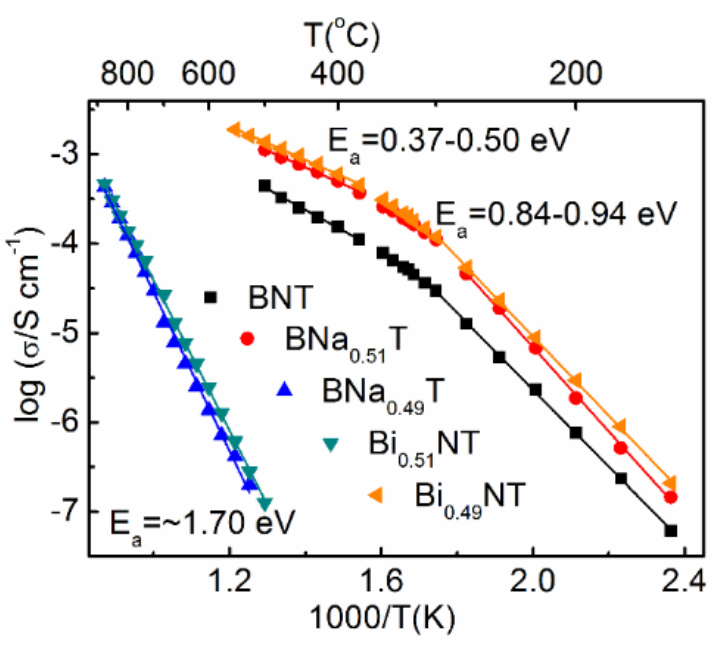

Figure 5. Arrhenius-type plots of bulk conductivity for nominal compositions $\mathrm{Bi}_{0.5} \mathrm{Na}_{0.5} \mathrm{TiO}_{3}$ (BNT), $\mathrm{Bi}_{0.49} \mathrm{Na}_{0.5} \mathrm{TiO}_{2.985}\left(\mathrm{Bi}_{0.49} \mathrm{NT}\right), \mathrm{Bi}_{0.51} \mathrm{Na}_{0.5} \mathrm{TiO}_{3.015}\left(\mathrm{Bi}_{0.51} \mathrm{NT}\right), \mathrm{Bi}_{0.5} \mathrm{Na}_{0.49} \mathrm{TiO}_{2.995}\left(\mathrm{BNa}_{0.49} \mathrm{~T}\right)$ and $\mathrm{Bi}_{0.5} \mathrm{Na}_{0.51} \mathrm{TiO}_{3.005}\left(\mathrm{BNa}_{0.51} \mathrm{~T}\right)$ (from references [102,103]).

For the nominal (starting) stoichiometric $\mathrm{BNT}$, loss of $\mathrm{Bi}_{2} \mathrm{O}_{3}$ during sample processing could lead to formation of oxygen vacancies. Starting compositions with Bi-deficiency (e.g., $\mathrm{Bi}_{0.49} \mathrm{BT}$ ) have additional oxygen vacancies and therefore exhibit higher oxide ion conductivity, whereas starting compositions with excess $\mathrm{Bi}_{2} \mathrm{O}_{3}$ (e.g., $\mathrm{Bi}_{0.51} \mathrm{NT}$ ) could suppress the oxygen and bismuth vacancy concentration and the oxide ion conductivity.

It is interesting to note that $\mathrm{Na}$ nonstoichiometry in the starting composition influences the electrical properties in a different way compared to Bi nonstoichiometry [102,103]. For example, compositions with $\mathrm{Na}$ deficiency are insulating, behaving similarly to compositions with Bi excess. Compositions with $\mathrm{Na}$ excess are conducting, behaving similarly to compositions with Bi deficiency. This appears confusing, as one expects the Na excess should help compensate A-site cation loss and suppress oxygen vacancies whereas $\mathrm{Na}$ deficiency should create oxygen vacancies and give higher oxide ion conductivity. SEM/TEM work on the presence of secondary phases clarified the origins of the apparent peculiar behavior. In the Na deficient composition $\left(\mathrm{BNa}_{0.49} \mathrm{~T}\right)$, TEM results reveal the presence of $\mathrm{TiO}_{2}$ secondary phase [103]. By renormalizing the composition to $\mathrm{Bi}_{0.51} \mathrm{Na}_{0.50} \mathrm{Ti}_{1.02} \mathrm{O}_{3.065}$ and considering it as $\mathrm{Bi}_{0.51} \mathrm{Na}_{0.50} \mathrm{Ti}_{1.02-x} \mathrm{O}_{3.055-2 x}+x \mathrm{TiO}_{2}\left(x \mathrm{TiO}_{2}\right.$ represents the $\mathrm{TiO}_{2}$ secondary phase), it is apparent the $\mathrm{BNa}_{0.49} \mathrm{~T}$ composition is effectively Bi-excess and therefore behaves similarly to $\mathrm{Bi}_{0.51} \mathrm{NT}$. On the other hand, the Na-excess composition $\mathrm{BNa}_{0.51} \mathrm{~T}$ can be considered as Bi-deficient due to $\mathrm{Bi}$ loss during sample processing and therefore behave similarly to $\mathrm{Bi}_{0.49} \mathrm{NT}$.

It should be stressed the nonstoichiometry level in BNT is low. Secondary phases are observed in the nonstoichiometric starting compositions [102,103]. Compositional analysis using 
scanning electron microscopy-energy dispersive spectrometry (SEM-EDS) at a local (grain) scale and inductively coupled plasma-atomic emission spectroscopy (ICP-AES) on the overall composition [102] revealed no appreciable bulk compositional differences between these samples. It is found that even $0.5-1 \mathrm{at} \% \mathrm{Nb}$ donor doping can fill the oxygen vacancies and suppress the oxide ion conductivity [67,102]. This suggests the nonstoichiometry in BNT is in the range of 0.0017-0.0033 for bismuth and 0.0025-0.0050 for oxygen. Clearly, the electrical properties of BNT are highly sensitive to low levels of nonstoichiometry. Similarly to that commonly observed in PZT, the generation/suppression of oxygen vacancies influence ferroelectric and piezoelectric properties including dielectric loss, coercive field, domain wall movement, fatigue, $T_{\mathrm{d}}$, $\mathrm{d}_{33}$, etc. Careful control of starting compositions and processing conditions is therefore crucible to obtain desirable and reproducible samples.

\section{Polarization and Strain Curves}

The phase diagrams of BNT and its various solid solutions (BNT-BT, BNT-BKT) manifest themselves in the polarization and strain curve in that way that well below the depolarization temperature $T_{\mathrm{d}}$ the polarization curve looks like a classical ferroelectric hysteresis curve. The same is true for the strain curve. It is a typical "butterfly" curve with a remanent strain. Approaching $T_{\mathrm{d}}$, the polarization curve gets pinched reminding on an antiferroelectric polarization curve. The remanent strain in the strain curves is reduced and the minima at coercive field become broader. Well above $T_{\mathrm{d}}$ the pinching of the polarization curve disappears and a very slim hysteresis curve develops, which is typical for a relaxor material. The strain curve completely loses its butterfly form and gets "sprout" shaped.

This shape change can be achieved either by increasing temperature or by changing chemical composition. Examples are nicely shown by Krauss, et al. [109] for the compositional change in the BNT-ST system (Figure 6) or by Wook Jo, et al. [110] for compositional and temperature change in the BNT-BT-KNN system. As can be seen from phase diagrams of BNT-BT [72] or BNT-BKT [111] $T_{\mathrm{d}}$ is minimized at regions addressed as morphotropic phase boundaries in solid solutions of rhombohedral BNT and a tetragonal compound (around $6 \mathrm{~mol} \% \mathrm{BT}$ or $17 \mathrm{~mol} \% \mathrm{BKT}$ ). The substitution of A-site cations with Rare Earth cations such as $\mathrm{Nd}^{3+}$ also effectively decreases $T_{\mathrm{d}}$.

It is worth mentioning that the appearance of a pinched hysteresis loop in these materials is observed at temperatures up to $70 \mathrm{~K}$ lower than the denoted depolarization temperature in the phase diagram. Such phase diagrams are usually derived from temperature dependent capacitance and loss factor measurements under low signal AC conditions (e.g., $0.1-1$ Vrms at $10 \mathrm{kHz}$ [112]). $T_{\mathrm{d}}$ is assigned to a maximum in the loss factor, which shows pronounced frequency dispersion. This frequency dispersion is at least to some minor extent responsible for the abovementioned temperature difference because hysteresis curves are measured at much lower frequencies, e.g., $0.1 \mathrm{~Hz}$. The major reason for the discrepancy is most probably the phase transition that is induced by large electric fields, which was shown clearly by Ma, et al. [91] for the BNT-BT solid solution. In this paper, this group enfolds a phase diagram of electric field vs. composition. In the range of 6-7 mol \% BT it could be proven by combination of in-situ TEM structural analysis and large signal $\mathrm{d}_{33}$ measurements on bulk samples that the material undergoes an irreversible phase transition from a relaxor ferrielectric with $\mathrm{P} 4 \mathrm{bm}$ symmetry into a mixed phase of $\mathrm{R} 3 \mathrm{c} / \mathrm{P} 4 \mathrm{~mm}$ symmetry, which is assigned ferroelectric, above $3 \mathrm{kV} / \mathrm{mm}$. This mixed phase shows higher $\mathrm{d}_{33}$ values than the virgin P4bm phase. Thus, it can be stated, that the origin of the large field induced strain is a ferrielectric-ferroelectric phase transition generated by the external electric field. It was also shown that at $6 \mathrm{~mol} \% \mathrm{BT}$ this mixed phase can be destroyed at electric fields exceeding $5 \mathrm{kV} / \mathrm{mm}$ resulting in a single $\mathrm{R} 3 \mathrm{c}$ phase with lower $\mathrm{d}_{33}$ values. 

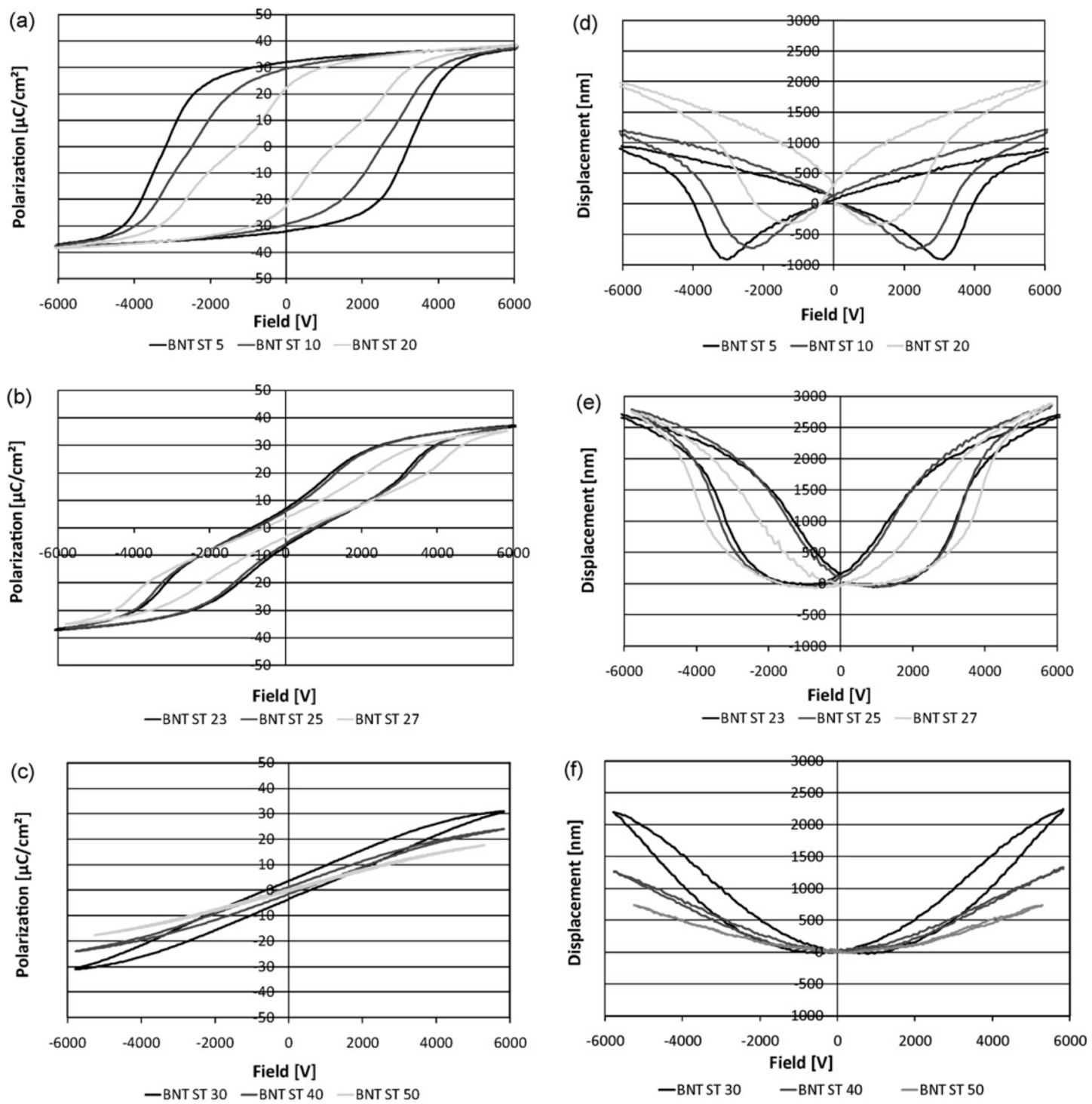

Figure 6. Polarization and displacement curves for the system $(100-x)\left(\mathrm{Bi}_{0.5} \mathrm{Na}_{0.5}\right) \mathrm{TiO}_{3}-x \mathrm{SrTiO} 3(\mathrm{x}=5$, $10,20(\mathbf{a}, \mathbf{d}), x=23,25,27(\mathbf{b}, \mathbf{e}), x=30,40,50(\mathbf{c}, \mathbf{f})$, reprinted from reference [109] with copyright from Elsevier 2010).

As an example of a typical strain curve (Figure 7) one is taken from the publication of Zhang, et al. [18] where the giant field induced strain was reported on the solid solution (1-x-y) $\left[\mathrm{Bi}_{0.5} \mathrm{Na}_{0.5} \mathrm{TiO}_{3}\right] x\left[\mathrm{BaTiO}_{3}\right]$ y $\left[\mathrm{K}_{0.5} \mathrm{Na}_{0.5} \mathrm{NbO}_{3}\right]$ for $x=0.06$ and $y=0.02$. A closer look reveals three distinct regions. Up to approximately $1 \mathrm{kV} / \mathrm{mm}$, a low strain region (1) of a weak ferroelectric is observed with $\mathrm{d}_{33}$ values around $40 \mathrm{pm} / \mathrm{V}$. Between 1 and $4 \mathrm{kV} / \mathrm{mm}$, an electrostrictive region (2) with a second order curvature follows, which can be assigned to the relaxor ferrielectric mentioned above, and, Finally, at higher field, a ferroelectric part (3) exhibiting an almost linear (first-order) curve is observed, which fades out into saturation. 


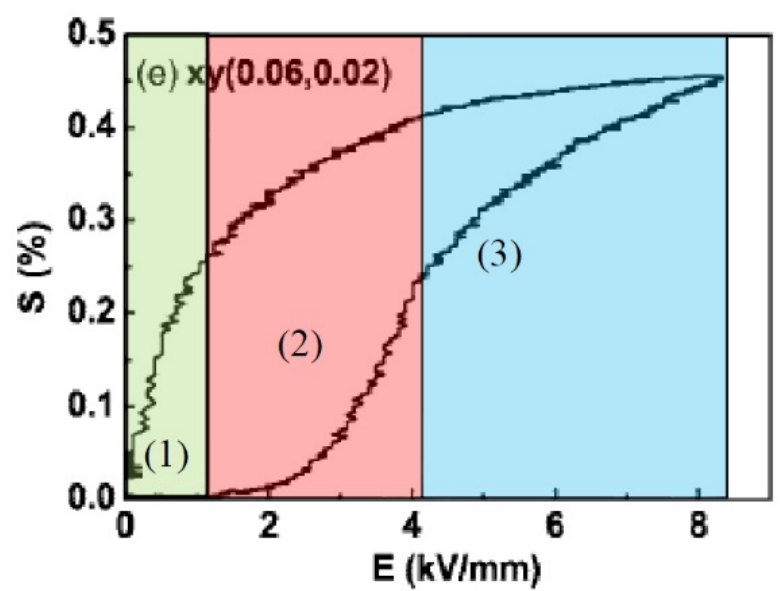

Figure 7. The positive part of the strain versus applied electric field loops for 92 BNT-6BT-2KNN. The regions indicated in the diagram are responsible for the peculiar electromechanical behavior and are related to a particular structure of the material: (1) low-strain region, weak ferroelectric; (2) electrostrictive region, relaxor ferrielectric; and (3) ferroelectric linear region (reprinted with permission from reference [18]. Copyright from AIP Publishing LLC 2008).

The studies of Zhang, et al. [113] proved that the strain of the system $(1-x-y)\left[\mathrm{Bi}_{0.5} \mathrm{Na}_{0.5} \mathrm{TiO}_{3}\right]$ $x\left[\mathrm{BaTiO}_{3}\right] y\left[\mathrm{~K}_{0.5} \mathrm{Na}_{0.5} \mathrm{NbO}_{3}\right]$ for $x=0.06$ and $y=0.02$ exceeds the strain of a soft PZT by more than $50 \%$ (Figure 8 ). The lead-free system exhibits a maximum strain of $0.45 \%$ at $8 \mathrm{kV} / \mathrm{mm} v \mathrm{~s} .0 .3 \%$ for soft PZT, which saturated at $4 \mathrm{kV} / \mathrm{mm}$. So promising this extraordinarily high strain is, the comparison also reveals the challenges, when replacing PZT with a BNT system in actuators. First, the maximum strain is achieved at much higher electric fields, which is an issue for lifetime prediction. Second, the area in the hysteresis loop is much larger, which means higher losses and a higher self-heating. The third issue is not obvious from Figure 8, but comes from the fact that this extraordinarily high strain is achieved for compositions operated at or near $T_{d}$. This results in a high temperature dependence of the strain. In a later publication, Zhang, et al. [18] denoted for the given example at $180{ }^{\circ} \mathrm{C}$ less than half of the strain measured at ambient conditions. Finally there is the question about the work an actuator can render. This in fact is the product of strain and force. In the following, we discuss the features that need to be addressed for the design of a material used for actuator applications.
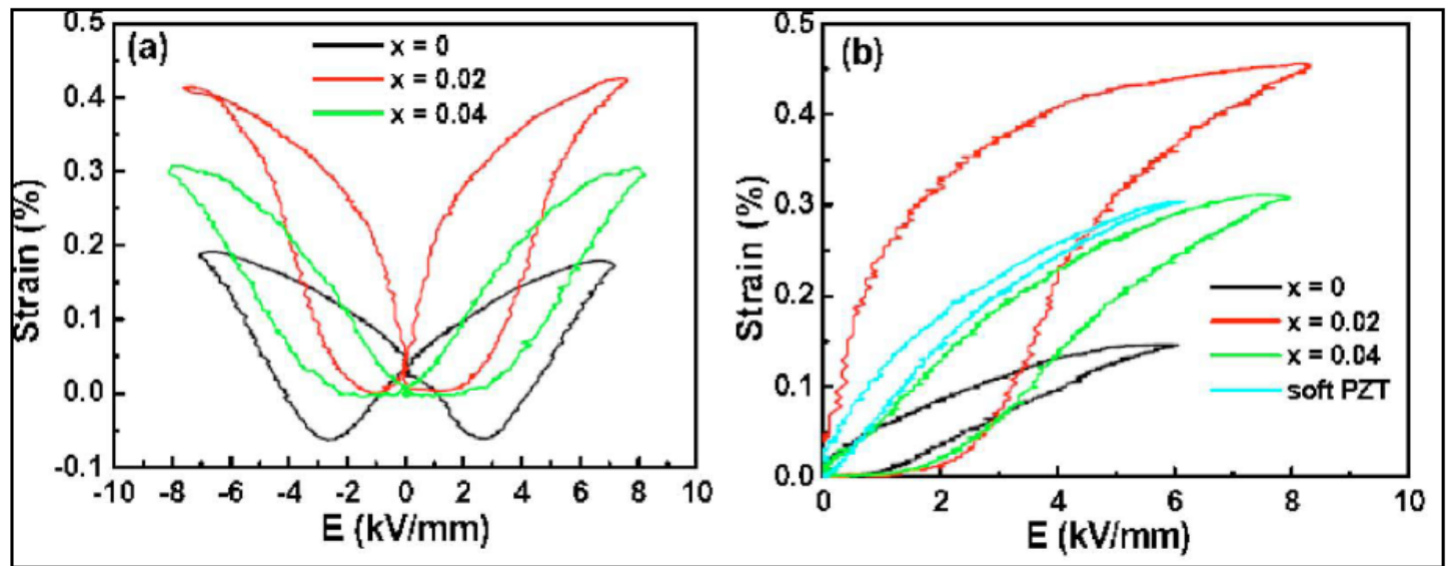

Figure 8. Bipolar (a) and unipolar (b) strain curves of (0.94-x)BNT-0.06BT-xKNN in comparison with a soft PZT (reprinted with permission from reference [113]. Copyright from AIP Publishing LLC 2007). 


\section{Texturing of Lead-Free Piezoelectric Ceramics}

Texturing of ceramic microstructures is a process that promotes preferred orientation of grains (crystals) along specific crystallographic directions, the establishment of large anisometric grains and even the orientation of defects. This preferred orientation can either enhance or compromise the performance of ceramic components. Until the 1990s, most of the research onto textured ceramics was mainly focused on high temperature superconductors and ceramic components for structural applications. Lately, crystallographic texturing of ferroelectric ceramics has been regarded as an opportunity to exploit the anisotropic character of piezoelectric crystals and achieve significant enhancements in the piezoelectric response of $\mathrm{Pb}$-free ceramics. For example, textured piezoceramics exhibit piezoelectric coefficients that can be two to three times higher than those shown by their randomly oriented counterparts and as high as $90 \%$ of the single-crystal values. Basically, the orientation of grains along preferred crystallographic directions promotes a more efficient alignment of polar vectors, leading to an increased poling efficiency and thereby an enhanced electromechanical response for a piezoceramic component. This is particularly beneficial for piezoelectrics where only two antiparallel states are allowed, because in microstructures encompassing randomly oriented grains, the percolation of the polarization is inhibited by grains which do not have possible domains states nearly aligned with the applied electric field. In principle those grains are not switchable and will prevent the switching of neighboring grains, which may actually have domains oriented more favorably with the applied field.

In the BNT-BT system, rhombohedral single-crystal can exhibit an electric-filed induced strain along the $<100>$ as large as $0.25 \%$, whereas tetragonal crystals show an even larger strain as high as $0.85 \%$, but with large hysteresis along the same direction [114]. It is believed that the exceptionally high strain of the tetragonal crystals arises from domain switching. These giant strain values are suitable for actuator applications, such fuel injectors, therefore BNT-based ceramics with textured microstructures have attracted significant scientific and commercial interest in recent years.

The first proposal of texturing of piezoelectric dates back to the late 1960s, and it was suggested for SbSi. This proposal was then extended in the mid-1980s to bismuth-layered ferroelectrics and tungsten bronzes, however in the following years research into texturing of piezoelectric undergone little progress and it was not until the late 1990s that a promising method for texturing perovskite-structured ferroelectrics emerged. Indeed, in 1998, T. Tani [115] from the Toyota Central Research and Development Laboratories, proposed the fabrication of BNT by a reactive template grain growth (RTGG) method.

Other methods exist for the fabrication of textured piezoceramics, which can be categorized as follows: (1) oriented consolidation of anisometric particles (OCAP); (2) templated grain growth (TGG); and (3) heterotemplated grain growth (HTGG). For details on these techniques, the reader is referred to excellent reviews by Kimura [116] and Messing, et al. [117]. Nevertheless, it is worth to mention that all these methods tend to rely on sintering of green compacts containing pre-aligned anisometric particles. Currently, it is still difficult to obtain fully textured piezoelectric ceramics, because processing parameters have not yet been completely optimized, but texturing has been extensively employed for the development of $\mathrm{Pb}$-free piezoelectric ceramics. Hereafter, we are reviewing chronologically the major advances achieved by texturing BNT-based piezoceramics.

As aforementioned the first attempt to induce texture in a BNT-based ceramic was conducted in 1998 by Tani [115], who employed the RTGG method to fabricate BNT ceramics. This process involves in-situ formation of a guest material $\left(\mathrm{Bi}_{0.5} \mathrm{Na}_{0.5} \mathrm{TiO}_{3}, \mathrm{BNT}\right)$ onto anisotropic oriented host particles $\left(\mathrm{Bi}_{4} \mathrm{Ti}_{3} \mathrm{O}_{12}, \mathrm{BIT}\right)$, a host-to-guest reaction, followed by grain growth to lead to a single-phase oriented microstructure. Basically, Tani [115] prepared large anisometric BIT particles $(5 \mu \mathrm{m} \times 5 \mu \mathrm{m} \times 0.2 \mu \mathrm{m})$ by a molten salts route, and then mixed those with $\mathrm{Bi}_{2} \mathrm{O}_{3}, \mathrm{Na}_{2} \mathrm{CO}_{3}$ and $\mathrm{TiO}_{2}$ in ethanol and toluene. Green sheets containing aligned BIT were formed by tape casting and subsequently laminated. BNT was formed by in-situ reactions between BIT and the other starting materials. Tani [115] extended this process to the fabrication of textured $\mathrm{Bi}_{0.5} \mathrm{Na}_{0.5} \mathrm{TiO}_{3}-15 \mathrm{~mol} \% \mathrm{Bi}_{0.5} \mathrm{~K}_{0.5} \mathrm{TiO}_{3}$ (BNT-BKT). BNT-BKT 
ceramics prepared by the RTGG method exhibited $\sim 40 \%$ larger $\mathrm{K}_{\mathrm{p}}$ values and $\sim 60 \%$ larger $d_{31}$ values when compared with non-textured ceramics of the same composition as shown in Table 1.

Table 1. Properties for BNT-BKT ceramics prepared by different methods.

\begin{tabular}{cccc}
\hline Preparation Method & Conventional Sintering & RTGG Sintered & RTGG Hot-Pressed \\
\hline Relative density $(\%)$ & 99.2 & 97.0 & 98.6 \\
Lotgering factor & 0 & 0.92 & 0.90 \\
$\varepsilon_{33} / \varepsilon_{\mathrm{o}}$ (at $\left.1 \mathrm{kHz}\right)$ & 593 & 595 & 644 \\
$\tan \delta($ at $1 \mathrm{kHz})$ & 0.025 & 0.014 & 0.013 \\
Poisson's ratio & 0.250 & 0.180 & 0.176 \\
$K_{\mathrm{t}}$ & 0.427 & 0.443 & 0.467 \\
$K_{\mathrm{p}}$ & 0.295 & 0.402 & 0.431 \\
$d_{31}(\mathrm{pC} / \mathrm{N})$ & 36.7 & 57.4 & 63.1 \\
$g_{31}\left(10^{-3} \mathrm{Vm} / \mathrm{N}\right)$ & 7.21 & 11.2 & 11.4 \\
\hline
\end{tabular}

In 2000, Yilmaz, et al. [118] presented their preliminary results for [001] textured $\mathrm{Bi}_{0.5} \mathrm{Na}_{0.5} \mathrm{TiO}_{3}-5.5 \mathrm{~mol} \% \mathrm{BaTiO}_{3}$ ceramics prepared by a TGG process. Basically, those researchers employed tape casting to orientate molten salt synthesized (001) $\mathrm{SrTiO}_{3}$ platelets in a BNT matrix, as schematically illustrated in Figure 9. During firing, $\mathrm{Bi}_{0.5} \mathrm{Na}_{0.5} \mathrm{TiO}_{3}-5.5 \mathrm{~mol} \% \mathrm{BaTiO}_{3}$ nucleated and grew on the surface of the $\mathrm{SrTiO}_{3}$ templates, achieving a $94 \%$ textured microstructure. Later, these researchers also studied RTGG of $\mathrm{Bi}_{0.5} \mathrm{Na}_{0.5} \mathrm{TiO}_{3}-5.5 \mathrm{~mol} \% \mathrm{BaTiO}_{3}$ using $\mathrm{Bi}_{4} \mathrm{Ti}_{3} \mathrm{O}_{12}$ template particles. In that case, a texture fraction of $80 \%$ was obtained, as measured by the Lotgering factor [119].

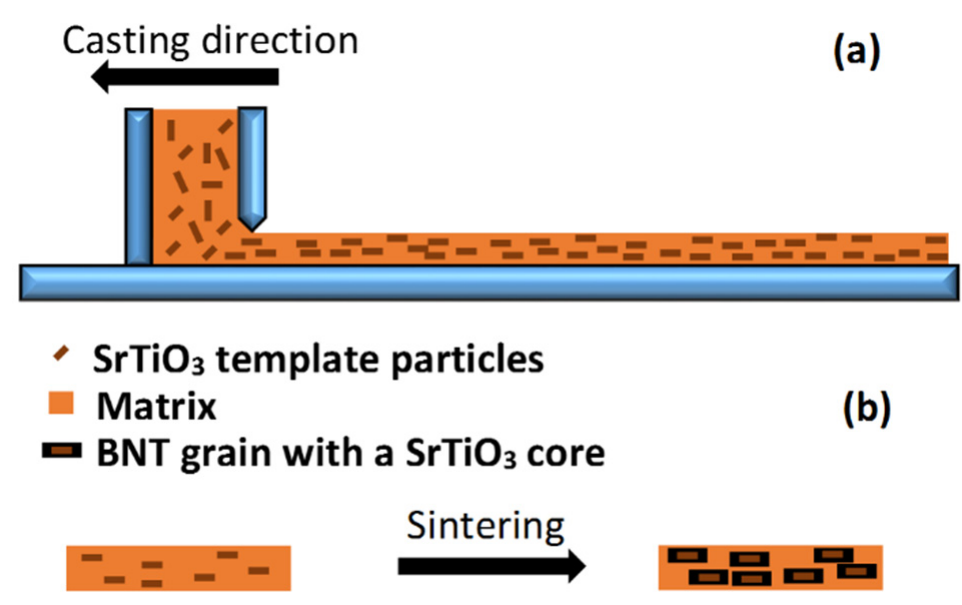

Figure 9. Schematics of template alignment by tape casting (a) and the texture fraction increases with heating (b) (based on reference [117]).

The maximum unipolar strain of $\mathrm{Bi}_{0.5} \mathrm{Na}_{0.5} \mathrm{TiO}_{3}-5.5$ mol \% $\mathrm{BaTiO}_{3}$ ceramics textured with $5.5 \mathrm{vol} \% \mathrm{SrTiO}_{3}$ template particles as function of Lotgering factor, is illustrated in Figure 10. It is apparent that for texture fractions lower than $70 \%$, the maximum strain is only moderately dependent on texture. Nevertheless, for texture fractions greater than $70 \%$ the maximum strain appears to increase significantly. For example, a sample with $94 \%$ texture shows $0.26 \%$ strain when measured at $70 \mathrm{kV} / \mathrm{cm}$ [119]. 


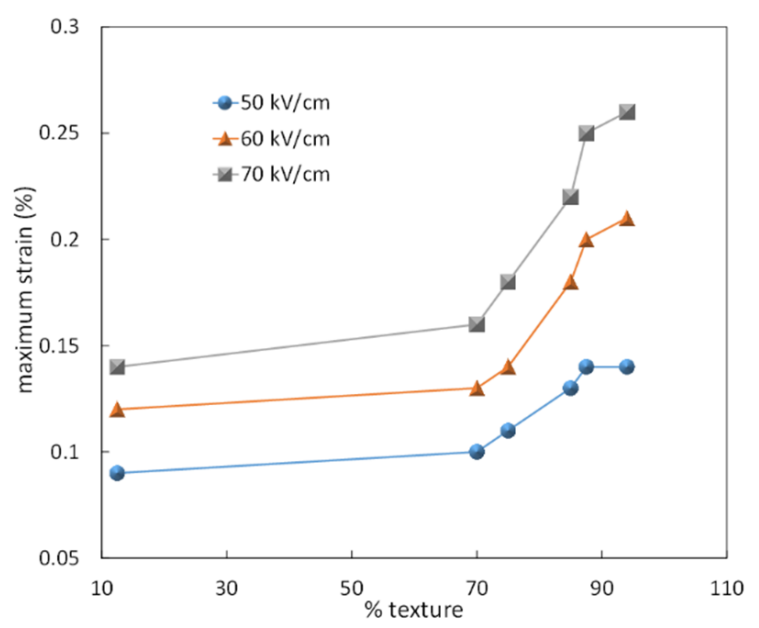

Figure 10. Unipolar Maximum strain of textured $\mathrm{Bi}_{0.5} \mathrm{Na}_{0.5} \mathrm{TiO}_{3}-5.5 \mathrm{~mol} \% \mathrm{BaTiO}_{3}$ ceramics textured with 6 vol \% $\mathrm{SrTiO}_{3}$ as function of the Lotgering factor.

In 2002, the RTGG process for $\mathrm{Bi}_{0.5}\left(\mathrm{Na}_{1-x} \mathrm{~K}_{x}\right)_{0.5} \mathrm{TiO}_{3}$ was studied in detail by Fukuchi, et al. [120], who proposed the following mechanism when starting with plate-like particles of BIT prepared by a molten salts route. Calcination promotes in-situ reactions as follows:

$$
\mathrm{Bi}_{4} \mathrm{Ti}_{3} \mathrm{O}_{12}+2(1-x) \mathrm{Na}_{2} \mathrm{CO}_{3}+2 x \mathrm{~K}_{2} \mathrm{CO}_{3}+5 \mathrm{TiO}_{2} \rightarrow 8 \mathrm{BNKT}+2 \mathrm{CO}_{2}
$$

and

$$
\mathrm{Bi}_{2} \mathrm{O}_{3}+(1-x) \mathrm{Na}_{2} \mathrm{CO}_{3}+x \mathrm{~K}_{2} \mathrm{CO}_{3}+4 \mathrm{TiO}_{2} \rightarrow 4 \mathrm{BNKT}+\mathrm{CO}_{2}
$$

Equation (2) forms plate-like BNKT particles (templates) with the crystallographic <100> direction perpendicular to the plate face and Equation (3) forms equiaxed BNKT particles (matrix) with random orientation. The oriented template particles grow at the expense of the matrix particles during sintering. In an alternative explanation, plate-like BNKT particles are formed due to $\mathrm{Na}_{2} \mathrm{O}$ and $\mathrm{K}_{2} \mathrm{O}$ diffusion into the BIT lattice, whereas small equiaxed BNKT particles (matrix) are formed by the reaction of $\mathrm{K}_{2} \mathrm{CO}_{3}, \mathrm{Na}_{2} \mathrm{CO}_{3}$ and $\mathrm{TiO}_{2}$ with $\mathrm{Bi}_{2} \mathrm{O}_{3}$ that diffuses out of BIT, as schematically illustrated in Figure 11.

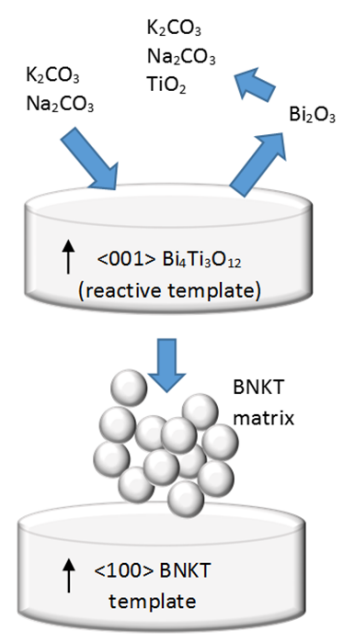

Figure 11. Schematic representation for the formation of BNKT templates from BIT particles and complementary reactants. 
In 2003, West and Payne [121] investigated both template and formulation effects on the microstructural development of BNT-based ceramics made by the RTGG method. Basically, they aimed to investigate the impact of both crystallography and chemistry of the template phase on the RTGG process. For this purpose they prepared $\mathrm{Sr}_{3} \mathrm{Ti}_{2} \mathrm{O}_{7}$ (Ruddlesden-Popper structured) and $\mathrm{BaBi}_{2} \mathrm{Nb}_{2} \mathrm{O}_{9}$ (Aurivillius structured) plate-like "templates" using a molten salts route, which were subsequently mixed with fine particles of BNT. It was found that perovskite formation was more sluggish in the mixtures templated with $\mathrm{Sr}_{3} \mathrm{Ti}_{2} \mathrm{O}_{7}$, and the final sintered microstructure featured larger, porous grains in an equiaxed, micrometer-sized matrix. They also postulated that successful RTGG processing of the BNT-based using Aurivillius templates could be achieved for matrix whose formulation contained excess alkali.

According to Kimura, et al. [122], there are two ways to develop crystallographic texture in BNT. One involves the addition of an excessive amount of $\mathrm{Bi}_{2} \mathrm{O}_{3}$ to promote preferential growth of oriented grains. Basically, in stoichiometric BNT, the growth rate of matrix grains is high and the conditions for the preferential growth of the oriented grains are disrupted. Nevertheless, excess $\mathrm{Bi}_{2} \mathrm{O}_{3}$ promotes preferential growth of oriented grains leading to the development of highly textured BNT. These textured BNT ceramics exhibit $70 \%$ higher piezoelectric $d_{31}$ and electromechanical $k_{\mathrm{p}}$ coefficients than non-textured BNT. A more effective way to achieve highly textured BNT microstructures is to increase the amount of plate-like BIT in the initial formulation. Kimura, et al. [122,123] prepared BNT and $\mathrm{Bi}_{0.5} \mathrm{Na}_{0.5} \mathrm{TiO}_{3}-6 \mathrm{~mol} \% \mathrm{BaTiO}_{3}$ bulk ceramics with extensive $<100>$ texture by the RTGG method, using plate-like BIT particles as templates for BNT. Because only BIT contributes to the formation of oriented grains, in order to increase volume of oriented grains the initial formulation needs to be modified, e.g., according to the following reaction

$$
\mathrm{BIT}+2 \mathrm{Na}_{2} \mathrm{CO}_{3}+5 \mathrm{TiO}_{2}=8 \mathrm{BNT}+2 \mathrm{CO}_{2}
$$

It is possible to supply $37.5 \% \mathrm{Ti}$ in the final product from plate-like BIT, and obtain highly textured BNT. Kimura, et al. [123] extended this formulation to prepare successfully prepare textured $\mathrm{Bi}_{0.5} \mathrm{Na}_{0.5} \mathrm{TiO}_{3}-6 \mathrm{~mol} \% \mathrm{BaTiO}_{3}$ ceramics. Interestingly the selection of $\mathrm{BaTiO}_{3}$ source $\left(\mathrm{BaTiO}_{3}\right.$ or $\mathrm{BaCO}_{3}+\mathrm{TiO}_{2}$ ) plays a remarkable role; $\mathrm{BaTiO}_{3}$ has little adverse effect on the texture development but $\mathrm{BaCO}_{3}+\mathrm{TiO}_{2}$ reduces the volume of oriented grains. Hence, texturing in BNT-BT ceramics is easily achieved if $\mathrm{BaTiO}_{3}$ is used as the source.

In 2006, Fuse and Kimura [124] studied the effect of particle sizes of starting materials on microstructure development in textured $\mathrm{Bi}_{0.5}\left(\mathrm{Na}_{0.5} \mathrm{~K}_{0.5}\right)_{0.5} \mathrm{TiO}_{3}$. During sintering texture develops by the growth of template grains at the expense of matrix grains. This grain growth rate is determined by the template and matrix grain sizes. Hence, textured $\mathrm{Bi}_{0.5}\left(\mathrm{Na}_{0.5} \mathrm{~K}_{0.5}\right)_{0.5} \mathrm{TiO}_{3}$ ceramics with a large degree of orientation and homogeneous microstructures are obtainable by the combination of small or medium BIT and small $\mathrm{TiO}_{2}$. Nevertheless, if the use of large BIT is desirable, textured ceramics without matrix grains are obtained by increasing the amount of BIT in the starting formulation. This is because the size of grains in the final microstructure is determined by the BIT particle size.

Researchers also started looking for alternative templates to BIT. For example, in 2006 Zeng, et al. [125] synthesized large plate-like BNT templates from the bismuth layer-structured ferroelectric $\mathrm{Na}_{0.5} \mathrm{Bi}_{4.5} \mathrm{Ti}_{4} \mathrm{O}_{15}$ (NBIT) particles. Owing to the similarity in structure between BNT and NBIT, it is possible to transform the layer-structured NBIT to a perovskite BNT by a topochemical method. Hence, large highly anisometric NBIT particles are first synthesized by the molten-salt process. After the topochemical reaction with the complementary reactants $\left(\mathrm{Na}_{2} \mathrm{CO}_{3}\right.$ and $\left.\mathrm{TiO}_{2}\right)$ in $\mathrm{NaCl}$ flux, the layer-structured NBIT particles are completely transformed into BNT, with retention of the plate-like morphology. These authors suggested these BNT templates to be effective at inducing grain orientation in the BNKT-BT ceramics in comparison with BIT templates. For a BNKT-BT ceramic textured with $20 \mathrm{wt} \%$ of BNT templates, they measured a Lotgering factor of 0.89 . The textured BNKT-BT ceramics templated by BNT showed $d_{33} \sim 215 \mathrm{pC} / \mathrm{N}$ compared with $167 \mathrm{pC} / \mathrm{N}$ for randomly oriented ceramics. Moreover, textured BNKT-BT ceramics templated by BIT show lower 
$d_{33} \sim 120 \mathrm{pC} / \mathrm{N}$, mainly due to their lower density. Zhao, et al. $[126,127]$ further corroborated the suitability of high-aspect-ratio BNT templates to obtain textured ceramics (especially BNT-based ceramics) by RTGG. For BNT- 6 mol $\% \mathrm{BaTiO}_{3}$ ceramics textured with 5 vol \% BNT templates, they obtained a Lotgering factor of 0.87 and a $d_{33}$ of $299 \mathrm{pC} / \mathrm{N}$.

In 2008, Gao, et al. [128] employed one-dimensional needle-like $\mathrm{KSr}_{2} \mathrm{Nb}_{5} \mathrm{O}_{15}$ (KSN) and two-dimensional plate-like $\mathrm{Bi}_{2.5} \mathrm{Na}_{3.5} \mathrm{Nb}_{5} \mathrm{O}_{18}$ particles, as templates to fabricate textured $\mathrm{Bi}_{0.5} \mathrm{Na}_{0.5} \mathrm{TiO}_{3}-\mathrm{BaTiO}_{3}$ ceramics by the RTGG method. They found that that KSN was unsuitable to fabricate textured ceramics, because the KSN particles were aligned randomly along the tape casting direction. In contrast, textured ceramics with orientation factor more than $60 \%$ could be successfully obtained using BNN particles as templates. Moreover, texture fraction increased with increasing BNN content, as expected.

In 2011, Maurya, et al. [129] use $\mathrm{Na}_{2} \mathrm{Ti}_{6} \mathrm{O}_{13}$ template whiskers prepared by molten salts for the preparation of textured BNT-7 mol \% $\mathrm{BaTiO}_{3}$ ceramics. Figure 12 shows a single tape of matrix containing well-aligned $\mathrm{Na}_{2} \mathrm{Ti}_{6} \mathrm{O}_{13}$ template whiskers. The highest $d_{33} \sim 216 \mathrm{pC} / \mathrm{N}$ was achieved for ceramics fired at $1200^{\circ} \mathrm{C}$.

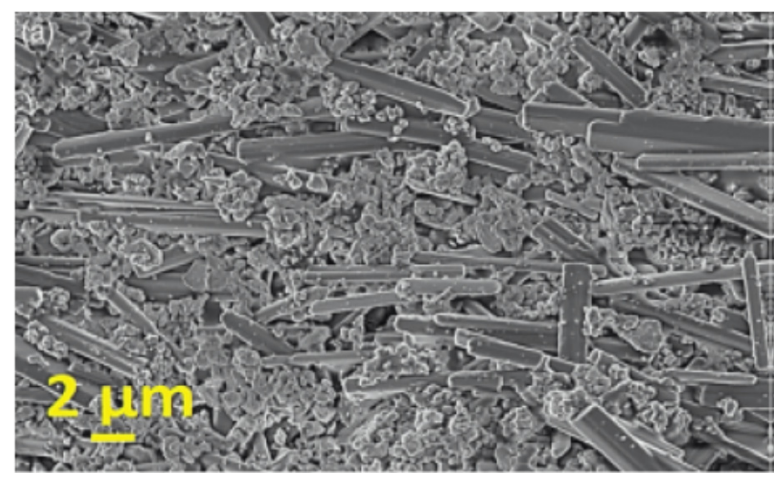

Figure 12. SEM image a single tape containing well-aligned $\mathrm{Na}_{2} \mathrm{Ti}_{6} \mathrm{O}_{13}$ template whiskers embedded in the base matrix powder [129].

In 2013, these researchers [130] synthesized again BNT-7 mol \% $\mathrm{BaTiO}_{3}$ but employing BNT seeds. They obtained ceramics with $92 \%$ textured microstructures, which exhibited a $200 \%$ improvement $d_{33} \sim 322 \mathrm{pC} / \mathrm{N}$, as compared to $160 \mathrm{pC} / \mathrm{N}$ for its randomly oriented counterparts. Later, Maurya, et al. [131] also fabricated grain-oriented lead-free ceramics from the $\mathrm{Bi}_{0.5} \mathrm{~K}_{0.5} \mathrm{TiO}_{3}-\mathrm{BaTiO}_{3}-\mathrm{xBi}_{0.5} \mathrm{Na}_{0.5} \mathrm{TiO}_{3}$ (BKT-BT-BNT) system with high degree of texturing along the $[001]_{\mathrm{c}}$ crystallographic orientation. In this case, they employed $\mathrm{BaTiO}_{3}$ seeds as the template particles. The textured specimens had depoling temperatures of more than $165^{\circ} \mathrm{C}$, revealing a higher stability temperature for lead-free piezoelectric systems. Moreover, textured ceramics exhibited a $\sim 70 \%$ increase in $d_{33}(\sim 190 \mathrm{pC} / \mathrm{N})$, and more than $200 \%$ increase in the $E$-field induced strain $(0.44 \%$ as compared to $0.23 \%$ in non-textured ceramics) with a ultra-low degree of hysteresis.

In 2014, $\mathrm{Hu}$, et al. [132] used a layered titanate $\mathrm{H}_{1.07} \mathrm{Ti}_{1.73} \mathrm{O}_{4} \cdot \mathrm{nH}_{2} \mathrm{O}(\mathrm{HTO})$ with a plate-like particle morphology as an alternative template to BIT or BNT for the fabrication of $<100>$ oriented BNT ceramics by RTGG. Nevertheless the improvement of the piezoelectric performance appeared to be modest.

Very recently, Hussain, et al. [133] prepared $0.94 \mathrm{Bi}_{0.5} \mathrm{Na}_{0.5} \mathrm{TiO}_{3}-0.06 \mathrm{BaZrO}_{3}$ (BNT-BZ) ceramics by a RTGG method using $15 \mathrm{wt} \%$ BNT as template particles. The as-synthesized BNT-BZ textured ceramics were sintered at $1150{ }^{\circ} \mathrm{C}$ for different firing times $(2-15 \mathrm{~h})$. These researchers observed that all textured BNT-BZ ceramics have (h00) preferred orientation, which increased with increasing sintering times. The depolarization temperature was unaltered by the sintering time. However, the field induced strain response increased by $20 \%$ when the sintering time was increased from $2 \mathrm{~h}$ to $15 \mathrm{~h}$. 
In addition, in 2015, Zhang, et al. [134] prepared by <100>-oriented $0.91 \mathrm{Bi}_{0.5} \mathrm{Na}_{0.5} \mathrm{TiO}_{3}-0.06 \mathrm{BaTiO}_{3}-0.03 \mathrm{AgNbO}_{3}$ ceramics with a Lotgering factor of 0.71 using plate-like BNT templates. A high unipolar strain of $0.38 \%$ and a large signal piezoelectric coefficient of $766 \mathrm{pm} / \mathrm{V}$ at $5 \mathrm{kV} / \mathrm{mm}$ was measured for these textured ceramics, which are $78 \%$ higher than the randomly oriented samples. It was found that textured ceramics exhibited significantly reduced frequency dependence in the unipolar strain behavior at room temperature, resulting from the decreased electric field required for the relaxor-ferroelectric phase transition. Both textured and randomly oriented ceramics have zero negative strains, suggesting the giant strain originated from a reversible electric field-induced phase transition, as expected for an incipient piezoelectric. With increasing temperature, increasing strain hysteresis almost vanishes and the induced ferroelectric state becomes negligible. Above $100{ }^{\circ} \mathrm{C}$, there is no electric field-induced phase transition with the applied electric field and therefore the electrostrictive response is the dominant contribution to the strain, which becomes similar to both ceramics. Temperature dependence of the strain for $0.91 \mathrm{Bi}_{0.5} \mathrm{Na}_{0.5} \mathrm{TiO}_{3}-0.06 \mathrm{BaTiO}_{3}-0.03 \mathrm{AgNbO}_{3}$ textured versus non-textured ceramics is illustrated in Figure 13.

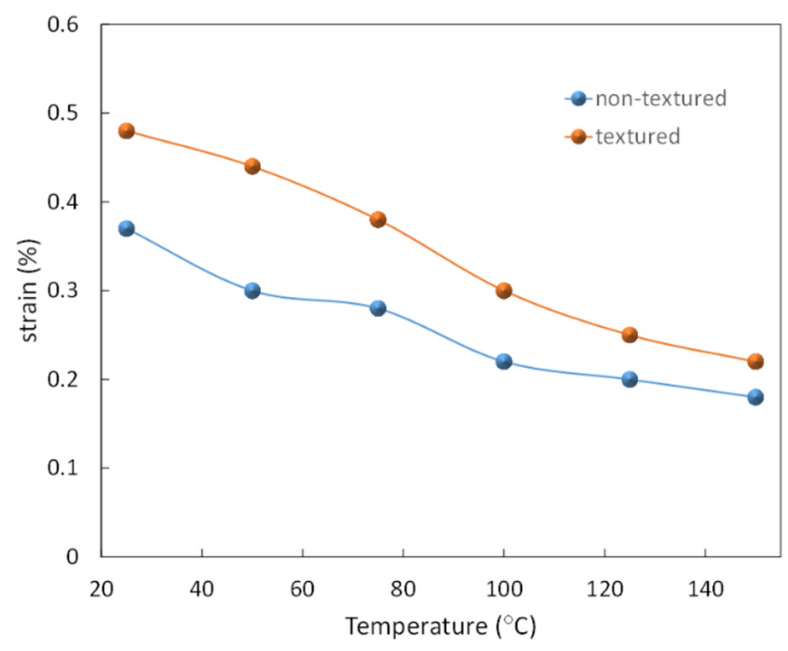

Figure 13. Temperature dependence of the strain for $0.91 \mathrm{Bi}_{0.5} \mathrm{Na}_{0.5} \mathrm{TiO}_{3}-0.06 \mathrm{BaTiO}_{3}-0.03 \mathrm{AgNbO}_{3}$ textured vs. non-textured ceramics (After Zhang, et al. [134]).

Key features of the aforementioned developments in textured microstructures for BNT-based ceramics are summarized in Table 2.

Table 2. Table illustrating the impact of texturing on the piezoelectric coefficients of BNT-based ceramics.

\begin{tabular}{|c|c|c|c|c|}
\hline $\begin{array}{l}\text { BNT-Based } \\
\text { System }\end{array}$ & $\begin{array}{l}\text { Template } \\
\text { Type }\end{array}$ & $\begin{array}{l}\text { Lotgering } \\
\text { Factor }(\%)\end{array}$ & $\begin{array}{l}\text { Small Signal Piezoelectric } \\
\text { Coefficient (pC/N) }\end{array}$ & Reference \\
\hline $\begin{array}{l}\text { BNT-15BKT } \\
\text { (hot-pressed) }\end{array}$ & $\mathrm{Bi}_{4} \mathrm{Ti}_{3} \mathrm{O}_{12}$ & $\sim 90$ & $d_{31}=63.1$ & Tani [115] \\
\hline BNT-5.5BT & $\mathrm{SrTiO}_{3}$ & $\sim 94$ & $d_{33}=200$ & Yilmaz, et al. [119] \\
\hline BNT-15BKT & $\mathrm{Bi}_{4} \mathrm{Ti}_{3} \mathrm{O}_{12}$ & $\sim 90$ & $d_{31}=50$ & Fukuchi, et al. [120] \\
\hline BNT-6BT & $\mathrm{Bi}_{4} \mathrm{Ti}_{3} \mathrm{O}_{12}$ & $\sim 90$ & $d_{31}=-31.4$ & Kimura, et al. [122] \\
\hline BNKT-BT & $\mathrm{Bi}_{0.5} \mathrm{Na}_{0.5} \mathrm{TiO}_{3}$ & $\sim 89$ & $d_{33}=215$ & Zheng, et al. [125] \\
\hline BNT-6BT & $\mathrm{Bi}_{0.5} \mathrm{Na}_{0.5} \mathrm{TiO}_{3}$ & $\sim 87$ & $d_{33}=299$ & Zhao, et al. [126] \\
\hline BNT-7BT & $\mathrm{Na}_{2} \mathrm{Ti}_{6} \mathrm{O}_{13}$ & $\sim 7$ & $d_{33}=216$ & Maurya, et al. [129] \\
\hline BNT-7BT & $\mathrm{Bi}_{0.5} \mathrm{Na}_{0.5} \mathrm{TiO}_{3}$ & $\sim 92$ & $d_{33}=322$ & Maurya, et al. [130] \\
\hline BNT-BT-BKT & $\mathrm{BaTiO}_{3}$ & $\sim 93$ & $d_{33}=190$ & Maurya, et al. [131] \\
\hline BNT-6BZ & $\mathrm{Bi}_{0.5} \mathrm{Na}_{0.5} \mathrm{TiO}_{3}$ & $\sim 83$ & $d_{33}=22$ & Hussain, et al. [133] \\
\hline BNT-6BT-3AN & $\mathrm{Bi}_{0.5} \mathrm{Na}_{0.5} \mathrm{TiO}_{3}$ & $\sim 71$ & $d_{33}=766$ at $5 \mathrm{kV}$ & Zhang, et al. [134] \\
\hline
\end{tabular}




\section{Features of Actuator Materials}

\subsection{Strain}

The strain over electric field of a soft PZT typically shows a butterfly curve. Usually an actuator is operated in unipolar mode. In this operation mode only the difference between maximum strain and remanent strain can be used for actuation. In rare cases an electric field of opposite polarity is applied well below the coercive field in order to increase the usable strain. A bipolar operation is prohibited because of the extremely high stresses that occur during reversal of polarity and a tremendous self-heating because of the intrinsic losses. The sprout shaped strain curve of a BNT based material near the depolarization temperature has a minimal remanent strain. Therefore the usable strain for actuation is much higher than in the case of a classical ferroelectric. In addition, a bipolar operation would be conceivable. However, as mentioned before, strain alone is not enough for the operation of an actuator. It is more the product of strain and force that expresses the energy or work that an actuator can deliver. Having in mind an actuator stack for opening the diesel injection valve in a combustion engine [135,136], this device makes a stroke of just about $40 \mu \mathrm{m}$ but against a fuel pressure of up to 2000 bar. Further, it has turned out advantageous to operate such a stack under pre-stress conditions, i.e., the device is mounted in a spring-like housing that exerts a load of about $30 \mathrm{MPa}$ to the stack [137]. This can optimize the usable strain and prevents disintegration by cracking.

\subsection{Blocking Force}

Usually two figures are given for a piezoelectric actuator, the free strain and the blocking force. The free strain is the strain on an actuator without any external load (technically users sometimes measure and refer to the free stroke, which should be normalized to the free strain to eliminate geometry factors). Usually it depends on the applied voltage in a linear manner up to the saturation. The blocking force is the maximum force an actuator can generate in clamped state (zero displacement) [138]. Since the blocking force also depends on the geometry of the actuator it is reasonable to refer to the blocking stress. Although both values are often cited to define the performance and work output of an actuator, it is obvious that in both cases the energy conversion is zero. To characterize the performance under mechanical load a rather sophisticated measurement setup has to be installed. In many cases, a good approximation of a strain/stress-diagram is obtained when the free strain and the blocking stress are connected by a straight line.

A careful measurement of blocking stress and energy conversion on BNT-based materials was performed by Dittmer, et al. [139]. The group selected BNT-6BT representing a ferroelectric at the morphotropic phase boundary similar to PZT, and BNT-6BT-2KNN, which can be considered a relaxor type material. The investigation included the dependence of free strain and blocking stress on electric field as well as on temperature. At room temperature, a linear increase of these two parameters with the applied field was observed for BNT-6BT. At $3 \mathrm{kV} / \mathrm{mm}$ a free strain of $0.064 \%$ and a blocking stress of $39 \mathrm{MPa}$ was measured yielding a maximum specific work of $3.5 \mathrm{~kJ} / \mathrm{m}^{3}$. This is much less than that of a soft PZT where a free strain of $0.19 \%$ and a blocking stress of $65 \mathrm{MPa}$ is obtained under the same electric field yielding a six times higher specific energy. The performance of BNT-6BT is rapidly increased by increasing temperature peaking at $125{ }^{\circ} \mathrm{C}$. Here free strain and blocking stress reach $0.26 \%$ and more than $100 \mathrm{MPa}$, respectively. Consequently, the specific energy yields $39 \mathrm{~kJ} / \mathrm{m}^{3}$, which significantly exceeds that of PZT, whose properties are much more temperature stable and increase about $10 \%-20 \%$ up to $150{ }^{\circ} \mathrm{C}$.

On the other hand, BNT-6BT-2KNN shows a strongly nonlinear increase of free strain and blocking stress with increasing electric field, which is due to the field induced phase transition that occurs in this material already at room temperature. The values at $3 \mathrm{kV} / \mathrm{mm}(0.21 \%$ free strain and $124 \mathrm{MPa}$ blocking stress) exceed that of BNT-6BT and PZT by far. The maximum specific work of about $35 \mathrm{~kJ} / \mathrm{m}^{3}$ is three times higher than that of PZT. However, with increasing temperature these values decrease rapidly. Figure 14 illustrates the temperature and field dependence of free strain 
and blocking stress of these two materials. It makes clear that the temperature range where their properties exceed that of PZT is rather narrow. Therefore, efforts were undertaken to broaden this range. This topic will be discussed in the following section.

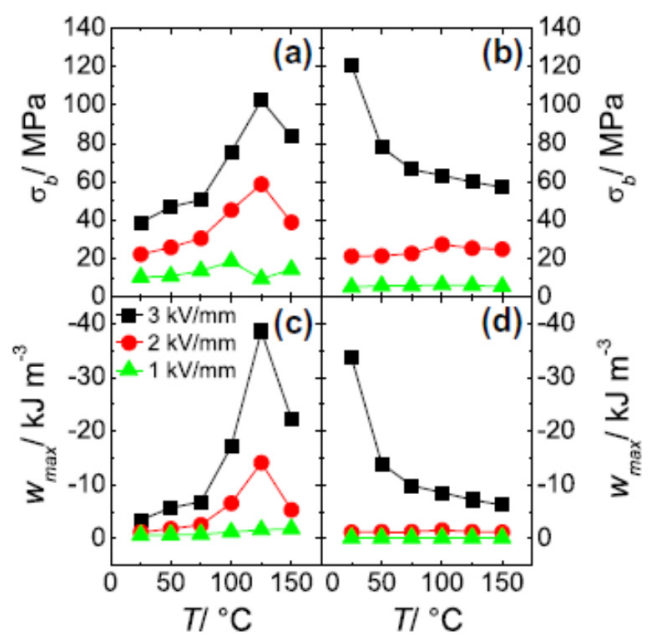

Figure 14. Blocking stress and maximum specific work for BNT-6BT (a,c); and for BNT-6BT-2KNN (b,d) as a function of temperature (reprinted from Reference [139] with copyright from Elsevier 2012).

Investigation of strain curves under variable stress [140] was carried out on multilayer stacks consisting of 50 single layers made of BNT-BKT-BLT ceramics doped with $2 \mathrm{~mol} \% \mathrm{Nd}$, a material already optimized for increased temperature stability of electromechanical properties [141]. For the electromechanical characterization, a constant stress varying between 0.1 and $80 \mathrm{MPa}$ was applied on the stack and subsequently five unipolar voltage ramps corresponding to a maximum electric field of $8 \mathrm{kV} / \mathrm{mm}$ were applied. During the voltage cycling the stress was kept constant and the strain was measured.

Figure 15 depicts the effective strain of this stack depending on the applied stress. In the virgin sample an applied stress of only $0.1 \mathrm{MPa}$ reduces the strain to less than $0.1 \%$, which is roughly half of the free strain measured with a laser interferometer. Increasing stress leads to an increase of effective strain peaking at $5 \mathrm{MPa}$ with $0.17 \%$ (blue symbols in Figure 15). A further increase of the stress up to $80 \mathrm{MPa}$ slightly decreases the effective strain. When decreasing stress, the measured strain values follow the curve obtained under increasing stress conditions down to $5 \mathrm{MPa}$. Below this stress level the strain does not follow the initial curve but further increases and reaches the level of free strain at $1 \mathrm{MPa}$.

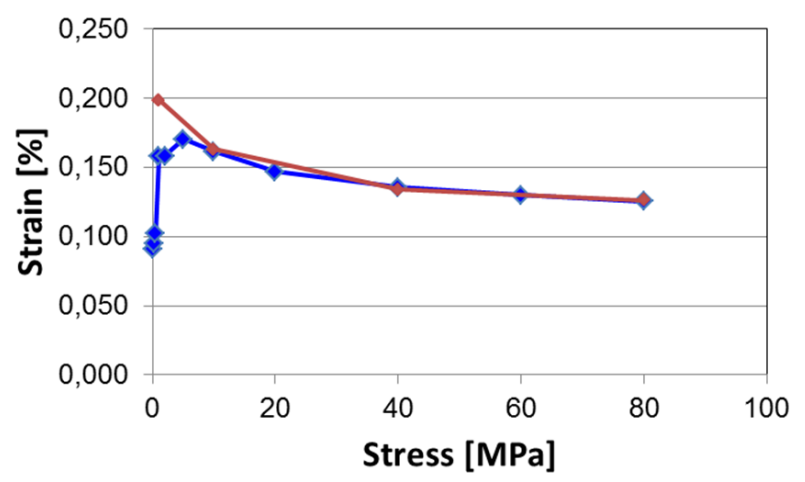

Figure 15. Effective strain of a stack actuator made of Nd-doped BNT-BKT-BLT at various stress levels at $8 \mathrm{kV} / \mathrm{mm}$ (blue symbols: increasing stress, red symbols: decreasing stress). 
This work revealed that such a material operating in the relaxor regime is capable of excerting a strain of $0.125 \%$ under a stress of $80 \mathrm{MPa}$, which is equivalent to a load of $3300 \mathrm{~N}$. This is comparable to commercial PZT based actuators used in fuel injection systems. The development of strain under increasing and decreasing stress gives evidence for a mechanically induced and irreversible transition.

\subsection{Temperature Dependence of Strain}

As mentioned above, BNT based ceramics show distinct maxima in strain at the so-called depolarization temperature $\mathrm{Td}$ as shown in the examples in the section "Blocking Force". Krauss, et al. [141] demonstrated on multilayer stacks with a BNT based material how to minimize the temperature dependence of strain. The approach was based on the concept to operate the actuator between depolarization temperature $T_{\mathrm{d}}$ and the temperature of maximum relative permittivity $T_{\mathrm{m}}$. This can be achieved by substitution of $\mathrm{Bi}$ and/or Na by smaller ions [16] or Ti by larger ions [142]. Obviously, such a substitution causes an increase of the A-site volume, which facilitates the phase transitions mentioned before [91]. Further solid solutions with tetragonal compounds like BaTiO3 [72,112] or BKT $[73,143]$ lead to a minimum in $\mathrm{T}_{\mathrm{d}}$ at the morphotropic phase boundary. Following these considerations the composition $\left[\mathrm{Bi}_{0.50} \mathrm{Na}_{0.335} \mathrm{~K}_{0.125} \mathrm{Li}_{0.04}\right] \mathrm{TiO}_{3}$ doped with $2 \mathrm{~mol} \%$ Neodymium was selected as ceramic material for the actuator stack. It is based on a BNT-BKT solid solution. The addition of $\mathrm{Li}$ and $\mathrm{Nd}$ increases the difference between $T_{\mathrm{d}}$ and $T_{\mathrm{m}}$. Figure 16a shows a narrow relaxor like polarization curve and a "sprout" shaped displacement curve with a maximum strain of $0.19 \%$ at $7 \mathrm{kV} / \mathrm{mm}$. This strain exhibits a variation of only $10 \%$ between 25 and $150{ }^{\circ} \mathrm{C}$ (Figure 16b).
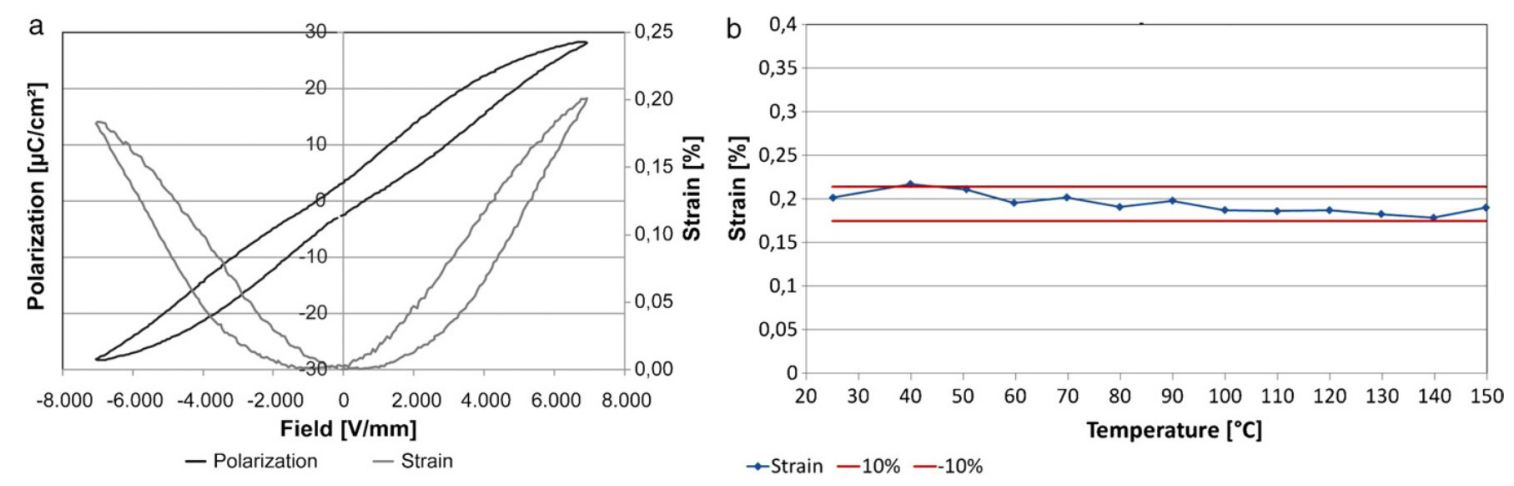

Figure 16. Polarization and displacement of a multilayer stack described by Krauss, et al. [141] at room temperature (a). Strain of the device at $7 \mathrm{kV} / \mathrm{mm}$ vs. temperature (b). Reprinted from [141] with copyright from Elsevier 2011.

\subsection{Degradation}

After extensive studies over the past two decades, optimized BNT-based compositions have been developed to compete well with PZT in certain areas. For commercial applications, these compositions must simultaneously have reliable performance for the required lifespan. Ferroelectric BNT-based materials exhibit higher coercive field than PZT. Performance degradation during electric loading is a concern for practical applications [144-146]. Indeed, for the composition $0.94 \mathrm{Bi}_{1 / 2} \mathrm{Na}_{1 / 2} \mathrm{TiO}_{3}-0.06 \mathrm{BaTiO}_{3}(94 \mathrm{BNT}-6 \mathrm{BT})$, which resembles a morphotropic phase boundary composition, a significant degradation in remanent polarization, strain, piezoelectric constant $d_{33}$ and relative permittivity $\varepsilon_{33}$ is observed even within the first $10^{4}$ cycles [147]. Micro-cracks are observed near the electrode region after $10^{4}$ cycles of bipolar cycling, which are considered to contribute significantly to the degradation of the ferroelectric properties. Degradation and cracking are reported to be suppressed by addition of 1 at $\% \mathrm{CuO}$ [148], which is attributed to either reduced defect charges 
(as demonstrated by lower conductivity) or reduced amount of rhombohedral phase and increased tetragonal phase fraction. It is considered that the rhombohedral phase is the main contributor to the macroscopic properties due to both $180^{\circ}$ and non- $180^{\circ}$ domain switching. In the tetragonal phase, the $90^{\circ}$ domain switching is suppressed due to the constraints of neighboring grains. Higher tetragonal phase fraction therefore leads to better fatigue resistance [148].

In one report, addition of KNN to BNT-BT $\left(0.91\left(\mathrm{Bi}_{1 / 2} \mathrm{Na}_{1 / 2}\right) \mathrm{TiO}_{3}-0.06 \mathrm{BaTiO}_{3}-0.03\left(\mathrm{~K}_{0.5} \mathrm{Na}_{0.5}\right) \mathrm{NbO}_{3}\right)$ is shown to improve the fatigue resistance [149]. However, a subsequent report [150] shows this composition suffers rapid degradation. Defective electrodes or defects within the ceramic rather than cracks resulting from high strain output are considered as the origins of degradation. It is interesting to note that the composition $0.92 \mathrm{Bi}_{1 / 2} \mathrm{Na}_{1 / 2} \mathrm{TiO}_{3}-0.08 \mathrm{BaTiO}_{3}(92 \mathrm{BNT}-8 \mathrm{BT})$ has higher tetragonal phase fraction and exhibits good fatigue resistance [150]. The decrease of strain is only $10 \%$ after $10^{8}$ cycles for the $92 \mathrm{BNT}-8 \mathrm{BT}$ ceramics. $\mathrm{Bi}\left(\mathrm{Zn}_{0.5} \mathrm{Ti}_{0.5}\right) \mathrm{O}_{3}(\mathrm{BZN})$ is reported to enhance fatigue resistance in the BNT-BT system [151] and BNT-BKT system [152].

\subsection{Interaction with Electrode}

High performance actuators operating at convenient voltage levels are usually manufactured by multilayer technology [135], which enables reducing ceramic layer thickness well below $100 \mu \mathrm{m}$. This technology includes co-firing of metal-ceramic-laminates, which strongly needs a good chemical and mechanical compatibility of these two constituents. Highly inert metals like Platinum might be appropriate for demonstrator devices but are commercially hardly enforceable.

Most actuator devices based on PZT use silver-palladium alloys as inner electrodes. The silver-palladium ratio determines the melting point that has to be adjusted to the sintering temperature. Metal-ceramic interaction comprises the diffusion of the electrode material into the ceramic and the formation of secondary phases at the metal ceramic interface leading to changes in the electrical properties of the ceramics or to delamination and loss of contact. In silver-palladium alloys the oxidation of palladium is observed between 300 and $835^{\circ} \mathrm{C}$ constituting a secondary phase that can react with the ceramic. Further, the $\mathrm{Ag} / \mathrm{Pd}$ ratio of the metal alloy is shifted to higher Ag-content causing a higher mobility and volatility of Ag. Another issue is the volume expansion, which can reach $15 \%[135,153]$. The amount of $\mathrm{PdO}$ formed can be minimized by increasing the heating rate in the relevant temperature range.

$\mathrm{PdO}$ together with $\mathrm{Bi}_{2} \mathrm{O}_{3}$ forms the compound $\mathrm{Bi}_{2} \mathrm{PdO}_{4}$ in the temperature range between $350{ }^{\circ} \mathrm{C}$ and $835^{\circ} \mathrm{C}[154,155]$. After decomposition at $835^{\circ} \mathrm{C}$, even the formation of the intermetallic compound $\mathrm{Pd}_{x} \mathrm{Bi}_{y}$ was observed. Thus, the use of silver-palladium alloy together with Bismuth-based ceramics was generally excluded and the first multilayer sample described by Nagata, et al. [156] contained platinum electrodes. In a study by Schütz, et al. [157] it was shown that the bismuth-palladium reaction does not take place if the presence of free $\mathrm{Bi}_{2} \mathrm{O}_{3}$ in the ceramic is avoided. This encouraged the use of silver palladium alloys for BNT-based multilayer devices.

To reduce the mechanical stress in multilayer devices during co-firing due to different onset of shrinkage and different thermal expansion coefficient the addition of ceramic powder to the electrode paste was used already for multilayer ceramic capacitors based on Barium Titanate. There usually sol-gel derived Barium Titanate powder with grain size around $100 \mathrm{~nm}$ is part of the nickel paste for inner electrodes. Such a concept for composite electrodes was suggested for lead free multilayer actuators based on BNT-BKT solid solution by Nguyen, et al. [158]. They applied a composite electrode consisting of Silver-Palladium alloy and powder of Potassium-Sodium-Niobate doped with Lithium and Tantalum. They observed the reduction of bending and cracking of the multilayer devices due to thermal mismatch and a three times higher normalized strain. Recently, Ahn, et al. [159] reported a significant reduction of sintering temperature for a BNT-BKT solid solution by addition of Copper Oxide from $1150{ }^{\circ} \mathrm{C}$ to $950{ }^{\circ} \mathrm{C}$. This reduction in sintering temperature decreases the thermal stress for multilayer components and therefore has a potential to minimize mechanical and 
chemical interaction. Moreover, the Palladium content of the inner electrode can be reduced, which significantly lowers materials cost.

\section{Summary}

Bismuth-Sodium-Titanate based solid solutions are interesting lead-free materials for actuator devices because of their extraordinarily high strain due to a phase transition induced by electric field. After the discovery of this effect, researchers worked for nearly one decade on revealing the structural features of these compounds and the peculiarities of the electromechanical behavior. It could be demonstrated that the observed strain can be used for effective work by determining blocking force, stress-strain-curves and the strain development under varying mechanical load. Texturing techniques have been developed that enable increasing the electromechanical coupling factor. For the application as actuators it was important to design and characterize multilayer devices containing inner electrodes. It could be shown that Silver-Palladium alloys, standard electrodes in multilayer ceramic components, can be used with BNT-based ceramics. All these findings are a good basis for the development of commercial devices. Still, to our best knowledge, there is only one company offering a BNT-based ceramic material and bulk actuator components made thereof (PI Ceramic, Lederhose, Germany). One of the reasons might be the fact that the investigation of long-term stability and degradation of these materials is still at the beginning and needs to be deepened in order to provide sufficient understanding for the development of reliable products, especially because such actuator devices most probably have to be operated at higher electric fields compared to devices based on PZT. This issue together with some cost factors (more expensive and challenging materials synthesis because of the water-soluble alkali compounds, noble metal electrodes) makes many industrial partners hesitate in the commercial use of these materials and the replacement of the well established PZT.

Acknowledgments: Antonio Feteira and Klaus Reichmann acknowledge the financial support of the Christian Doppler Research Association, the Federal Ministry of Science, Research and Economy, and EPCOS OHG, a group company of the TDK-EPC Corporation. Ming Li thanks the University of Nottingham for a Nottingham Research Fellowship.

Author Contributions: Authors contributed equally to this publication. In particular, Ming Li is responsible for Section 2 and Antonio Feteira authored Section 4.

Conflicts of Interest: The authors declare no conflict of interest.

\section{References}

1. Rödel, J.; Webber, K.G.; Dittmer, R.; Wook, J.; Kimura, M.; Damjanovic, D. Transferring lead-free piezoelectric ceramics into application. J. Eur. Ceram. Soc. 2015, 35, 1659-1681. [CrossRef]

2. Liu, W.F.; Ren, X.B. Large piezoelectric effect in Pb-free ceramics. Phys. Rev. Lett. 2009, 103. [CrossRef] [PubMed]

3. Damjanovic, D.; Biancoli, A.; Batooli, L.; Vahabzadeh, A.; Trodahl, J. Elastic, dielectric, and piezoelectric anomalies and Raman spec-troscopy of $0.5 \mathrm{Ba}\left(\mathrm{Ti}_{0.8} \mathrm{Zr}_{0.2}\right) \mathrm{O}_{3}-0.5\left(\mathrm{Ba}_{0.7} \mathrm{Ca}_{0.3}\right) \mathrm{TiO}_{3}$. Appl. Phys. Lett. 2012, 100, 192907. [CrossRef]

4. Ehmke, M.C.; Ehrlich, S.N.; Blendell, J.E.; Bowman, K.J. Phase coexistence and ferroelastic texture in high strain $(1-x) \mathrm{Ba}\left(\mathrm{Zr}_{0.2} \mathrm{Ti}_{0.8}\right) \mathrm{O}_{3}-x\left(\mathrm{Ba}_{0.7} \mathrm{Ca}_{0.3}\right) \mathrm{TiO}_{3}$. J. Appl. Phys. 2012, 111, 124110. [CrossRef]

5. Hao, J.; Bai, W.; Li, W.; Zhai, J. Correlation between the microstructure andelectrical properties in high-performance $\left(\mathrm{Ba}_{0.85} \mathrm{Ca}_{0.15}\right)\left(\mathrm{Zr}_{0.1} \mathrm{Ti}_{0.9}\right) \mathrm{O}_{3}$ lead-free piezoelectric ceramics. J. Am. Ceram. Soc. 2012, 95, 1998-2006. [CrossRef]

6. Brandt, D.R.J.; Acosta, M.; Koruza, J.; Webber, K.G. Mechanical constitutive behavior and exceptional blocking force of lead-free BZT- $x$ BCT piezoceramics. J. Appl. Phys. 2014, 115, 204107. [CrossRef]

7. Shrout, T.R.; Zhang, S.J. Lead-free piezoelectric ceramics: Alternatives for PZT? J. Electroceram. 2007, 19, 113-126. [CrossRef] 
8. Wang, K.; Yao, F.-Z.; Jo, W.; Gobeljic, D.; Shvartsman, V.V.; Lupascu, D.C.; Li, J.-F.; Rödel, J. Temperature-insensitive (K,Na) $\mathrm{NbO}_{3}$-based lead-free piezoactuator ceramics. Adv. Funct. Mater. 2013, 23, 4079-4086. [CrossRef]

9. Hollenstein, E.; Davis, M.; Damjanovic, D.; Setter, N. Piezoelectric properties of Li- and Ta-modified $\left(\mathrm{K}_{0.5} \mathrm{Na}_{0.5}\right) \mathrm{NbO}_{3}$ ceramics. Appl. Phys. Lett. 2005, 87, 182905. [CrossRef]

10. Matsubara, M.; Yamaguchi, T.; Kikuta, K.; Hirano, S. Sinterability and piezoelectric properties of $(\mathrm{K}, \mathrm{Na}) \mathrm{NbO}_{3}$ ceramics with novel sintering aid. Jpn. J. Appl. Phys. 2004, 43, 7159-7163. [CrossRef]

11. Dittmer, R.; Webber, K.G.; Aulbach, E.; Jo, W.; Tan, X.; Rödel, J. Electric-field-induced polarization and strain in $0.94\left(\mathrm{Bi}_{1 / 2} \mathrm{Na}_{1 / 2}\right) \mathrm{TiO}_{3}-0.06 \mathrm{BaTiO}_{3}$ under uniaxial stress. Acta Mater. 2013, 61, 1350-1358. [CrossRef]

12. Anton, E.-M.; Jo, W.; Damjanovic, D.; Rödel, J. Determination of depolarization temperature of $\left(\mathrm{Bi}_{1 / 2} \mathrm{Na}_{1 / 2}\right) \mathrm{TiO}_{3}$-based lead-free piezoceramics. J. Appl. Phys. 2011, 110, 094108. [CrossRef]

13. Takenaka, T.; Nagata, H. Current status and prospects of lead-free piezoelectric ceramics. J. Eur. Ceram. Soc. 2005, 25, 2693-2700. [CrossRef]

14. Zhang, S.-T.; Kounga, A.B.; Aulbach, E.; Deng, Y. Temperature-dependent electrical properties of 0.94Bi ${ }_{0.5} \mathrm{Na}_{0.5} \mathrm{TiO}_{3}-0.06 \mathrm{BaTiO}_{3}$ ceramics. J. Am. Ceram. Soc. 2008, 91, 3950-3954. [CrossRef]

15. Hiruma, Y.; Imai, Y.; Watanabe, Y.; Nagata, H.; Takenaka, T. Large electrostrain near the phase transition temperature of $\left(\mathrm{Bi}_{0.5} \mathrm{Na}_{0.5}\right) \mathrm{TiO}_{3}-\mathrm{SrTiO}_{3}$ ferroelectric ceramics. Appl. Phys. Lett. 2008, 92. [CrossRef]

16. Hiruma, Y.; Nagata, H.; Takenaka, T. Phase diagrams and electrical properties of $\left(\mathrm{Bi}_{1 / 2} \mathrm{Na}_{1 / 2}\right) \mathrm{TiO}_{3}$-based solid solutions. J. Appl. Phys. 2008, 104. [CrossRef]

17. Zhang, S.-T.; Kounga, A.B.; Jo, W.; Jamin, C.; Seifert, K.; Granzow, T.; Rodel, J.; Damjanovic, D. High-strain lead-free antiferroelectric electrostrictors. Adv. Mater. 2009, 21, 4716-4720. [CrossRef]

18. Zhang, S.T.; Kounga, A.B.; Aulbach, E.; Granzow, T.; Jo, W.; Kleebe, H.J.; Rödel, J. Lead-free piezoceramics with giant strain in the system $\mathrm{Bi}_{0.5} \mathrm{Na}_{0.5} \mathrm{TiO}_{3}-\mathrm{BaTiO}_{3}-\mathrm{K}_{0.5} \mathrm{Na}_{0.5} \mathrm{NbO}_{3}$. I. Structure and room temperature properties. J. Appl. Phys. 2008, 103, 034107. [CrossRef]

19. Zhang, S.T.; Kounga, A.B.; Aulbach, E.; Jo, W.; Granzow, T.; Ehrenberg, H.; Rödel, J. Lead-free piezoceramics with giant strain in the system $\mathrm{Bi}_{0.5} \mathrm{Na}_{0.5} \mathrm{TiO}_{3}-\mathrm{BaTiO}_{3}-\mathrm{K}_{0.5} \mathrm{Na}_{0.5} \mathrm{NbO}_{3}$. II. Temperature dependent properties. J. Appl. Phys. 2008, 103, 034108. [CrossRef]

20. Acosta, M.; Jo, W.; Rödel, J. Temperature and frequency dependent properties of the $0.75 \mathrm{Bi}_{1 / 2} \mathrm{Na}_{1 / 2} \mathrm{TiO}_{3}-0.25 \mathrm{SrTiO}_{3}$ lead-free incipient piezoceramic. J. Am. Ceram. Soc. 2014, 97, 1937-1943. [CrossRef]

21. Malik, R.A.; Kang, J.-K.; Hussain, A.; Ahn, C.-W.; Han, H.-S.; Lee, J.-S. High strain in lead-free Nb-doped $\mathrm{Bi}_{1 / 2}\left(\mathrm{Na}_{0.84} \mathrm{~K}_{0.16}\right)_{1 / 2} \mathrm{TiO}_{3}-\mathrm{SrTiO}_{3}$ incipient piezoelectric ceramics. Appl. Phys. Express 2014, 7, 061502. [CrossRef]

22. Saito, Y.; Takao, H.; Tani, T.; Nonoyama, T.; Takatori, K.; Homma, T.; Nagaya, T.; Nakamura, M. Lead-free piezoceramics. Nature 2004, 432, 84-87. [CrossRef] [PubMed]

23. Smolenskii, G.; Isupov, V.; Agranovskaya, A.; Krainik, N. New ferroelectrics of complex composition. Sov. Phys. Solid State 1961, 2, 2651-2654.

24. Buhrer, C.F. Some properties of bismuth perovskites. J. Chem. Phys. 1962, 36, 798-803. [CrossRef]

25. Ivanova, V.; Kapyshev, A.; Venevtsev, Y.N.; Zhdanov, G. X-ray determination of the symmetry of elementary cells of the ferroelectric materials $\left(\mathrm{K}_{0.5} \mathrm{Bi}_{0.5}\right) \mathrm{TiO}_{3}$ and $\left(\mathrm{Na}_{0.5} \mathrm{Bi}_{0.5}\right) \mathrm{TiO}_{3}$ and of high-temperature phase transitions in $\left(\mathrm{K}_{0.5} \mathrm{Bi}_{0.5}\right) \mathrm{TiO}_{3}$. Izv. Akad. Nauk SSSR Seriya Fiz. 1962, 26, 354-356.

26. Zvirgzds, J.A.; Kapostin, P.P.; Zvirgzde, J.V.; Kruzina, T.V. X-ray study of phase transitions in ferroelectric $\mathrm{Na}_{0.5} \mathrm{Bi}_{0.5} \mathrm{TiO}_{3}$. Ferroelectrics 1982, 40, 75-77. [CrossRef]

27. Glazer, A. The classification of tilted octahedra in perovskites. Acta Crystallogr. Sect. B 1972, 28, $3384-3392$. [CrossRef]

28. Vakhrushev, S.; Ivanitskij, B.; Kvyatkovskij, B.; Majstrenko, A.; Malysheva, R.; Okuneva, N.; Parfenova, N. Neutron-diffraction study on sodium-bismuth titanate. Sov. Phys. Solid State 1983, 25, 1504-1506.

29. Jones, G.O.; Thomas, P.A. Investigation of the structure and phase transitions in the novel A-site substituted distorted perovskite compound $\mathrm{Na}_{0.5} \mathrm{Bi}_{0.5} \mathrm{TiO}_{3}$. Acta Crystallogr. Sect. B 2002, 58, 168-178. [CrossRef]

30. Isuyov, V.A.; Pronin, I.P.; Kruzina, T.V. Temperature dependence of bireringence and opalescence of the sodium-bismuth titanate crystals. Ferroelectr. Lett. Sect. 1984, 2, 205-208. [CrossRef] 
31. Kreisel, J.; Bouvier, P.; Dkhil, B.; Thomas, P.A.; Glazer, A.M.; Welberry, T.R.; Chaabane, B.; Mezouar, M. High-pressure $X$-ray scattering of oxides with a nanoscale local structure: Application to $\mathrm{Na}_{1 / 2} \mathrm{Bi}_{1 / 2} \mathrm{TiO}_{3}$. Phys. Rev. B 2003, 68, 014113. [CrossRef]

32. Shuvaeva, V.A.; Zekria, D.; Glazer, A.M.; Jiang, Q.; Weber, S.M.; Bhattacharya, P.; Thomas, P.A. Local structure of the lead-free relaxor ferroelectric $\left(\mathrm{K}_{x} \mathrm{Na}_{1-x}\right)_{0.5} \mathrm{Bi}_{0.5} \mathrm{TiO}_{3}$. Phys. Rev. B 2005, 71, 174114. [CrossRef]

33. Balagurov, A.M.; Koroleva, E.Y.; Naberezhnov, A.A.; Sakhnenko, V.P.; Savenko, B.N.; Ter-Oganessian, N.V.; Vakhrushev, S.B. The rhombohedral phase with incommensurate modulation in $\mathrm{Na}_{1 / 2} \mathrm{Bi}_{1 / 2} \mathrm{TiO}_{3}$. Phase Transit. 2006, 79, 163-173. [CrossRef]

34. Keeble, D.S.; Barney, E.R.; Keen, D.A.; Tucker, M.G.; Kreisel, J.; Thomas, P.A. Bifurcated polarization rotation in bismuth-based piezoelectrics. Adv. Funct. Mater. 2012, 23, 185-190. [CrossRef]

35. Aksel, E.; Forrester, J.S.; Nino, J.C.; Page, K.; Shoemaker, D.P.; Jones, J.L. Local atomic structure deviation from average structure of $\mathrm{Na}_{0.5} \mathrm{Bi}_{0.5} \mathrm{TiO}_{3}$ : Combined X-ray and neutron total scattering study. Phys. Rev. B 2013, 87, 104113. [CrossRef]

36. Gorfman, S.; Thomas, P.A. Evidence for a non-rhombohedral average structure in the lead-free piezoelectric material $\mathrm{Na}_{0.5} \mathrm{Bi}_{0.5} \mathrm{TiO}_{3}$. J. Appl. Crystallogr. 2010, 43, 1409-1414. [CrossRef]

37. Aksel, E.; Forrester, J.S.; Jones, J.L.; Thomas, P.A.; Page, K.; Suchomel, M.R. Monoclinic crystal structure of polycrystalline $\mathrm{Na}_{0.5} \mathrm{Bi}_{0.5} \mathrm{TiO}_{3}$. Appl. Phys. Lett. 2011, 98, 152901. [CrossRef]

38. Aksel, E.; Forrester, J.S.; Kowalski, B.; Jones, J.L.; Thomas, P.A. Phase transition sequence in sodium bismuth titanate observed using high-resolution X-ray diffraction. Appl. Phys. Lett. 2011, 99, 222901. [CrossRef]

39. Rao, B.N.; Datta, R.; Chandrashekaran, S.S.; Mishra, D.K.; Sathe, V.; Senyshyn, A.; Ranjan, R. Local structural disorder and its influence on the average global structure and polar properties in $\mathrm{Na}_{0.5} \mathrm{Bi}_{0.5} \mathrm{TiO}_{3}$. Phys. Rev. B 2013, 88, 224103. [CrossRef]

40. Rao, B.N.; Ranjan, R. Electric-field-driven monoclinic-to-rhombohedral transformation in $\mathrm{Na}_{1 / 2} \mathrm{Bi}_{1 / 2} \mathrm{TiO}_{3}$. Phys. Rev. B 2012, 86, 134103. [CrossRef]

41. Rao, B.N.; Fitch, A.N.; Ranjan, R. Ferroelectric-ferroelectric phase coexistence in $\mathrm{Na}_{1 / 2} \mathrm{Bi}_{1 / 2} \mathrm{TiO}_{3}$. Phys. Rev. B 2013, 87, 060102. [CrossRef]

42. Beanland, R.; Thomas, P.A. Symmetry and defects in rhombohedral single-crystalline $\mathrm{Na}_{0.5} \mathrm{Bi}_{0.5} \mathrm{TiO}_{3}$. Phys. Rev. B 2014, 89, 174102. [CrossRef]

43. Dorcet, V.; Trolliard, G. A transmission electron microscopy study of the A-site disordered perovskite $\mathrm{Na}_{0.5} \mathrm{Bi}_{0.5} \mathrm{TiO}_{3}$. Acta Mater. 2008, 56, 1753-1761. [CrossRef]

44. Beanland, R.; Thomas, P.A. Imaging planar tetragonal sheets in rhombohedral $\mathrm{Na}_{0.5} \mathrm{Bi}_{0.5} \mathrm{TiO}_{3}$ using transmission electron microscopy. Scr. Mater. 2011, 65, 440-443. [CrossRef]

45. Levin, I.; Reaney, I.M. Nano- and mesoscale structure of $\mathrm{Na}_{1 / 2} \mathrm{Bi}_{1 / 2} \mathrm{TiO}_{3}$ : A TEM perspective. Adv. Funct. Mater. 2012, 22, 3445-3452. [CrossRef]

46. Ma, C.; Guo, H.; Tan, X. A new phase boundary in $\left(\mathrm{Bi}_{1 / 2} \mathrm{Na}_{1 / 2}\right) \mathrm{TiO}_{3}-\mathrm{BaTiO}_{3}$ revealed via a novel method of electron diffraction analysis. Adv. Funct. Mater. 2013, 23, 5261-5266. [CrossRef]

47. King, G.; Woodward, P.M. Cation ordering in perovskites. J. Mater. Chem. 2010, 20, 5785-5796. [CrossRef]

48. Davies, P.; Wu, H.; Borisevich, A.; Molodetsky, I.; Farber, L. Crystal chemistry of complex perovskites: New cation-ordered dielectric oxides. Annu. Rev. Mater. Res. 2008, 38, 369-401. [CrossRef]

49. Shannon, R.D. Revised effective ionic radii and systematic studies of interatomic distances in halides and chalcogenides. Acta Crystallogr. Sect. A 1976, 32, 751-767. [CrossRef]

50. Groeting, M.; Hayn, S.; Albe, K. Chemical order and local structure of the lead-free relaxor ferroelectric $\mathrm{Na}_{1 / 2} \mathrm{Bi}_{1 / 2} \mathrm{TiO}_{3}$. J. Solid State Chem. 2011, 184, 2041-2046. [CrossRef]

51. Park, S.E.; Chung, S.J.; Kim, I.T.; Hong, K.S. Nonstoichiometry and the long-range cation ordering in crystals of $\left(\mathrm{Na}_{1 / 2} \mathrm{Bi}_{1 / 2}\right) \mathrm{TiO}_{3}$. J. Am. Ceram. Soc. 1994, 77, 2641-2647. [CrossRef]

52. Siny, I.; Smirnova, T.; Kruzina, T. The phase transition dynamics in $\mathrm{Na}_{1 / 2} \mathrm{Bi}_{1 / 2} \mathrm{TiO}_{3}$. Ferroelectrics 1991, 124, 207-212. [CrossRef]

53. Petzelt, J.; Kamba, S.; Fabry, J.; Noujni, D.; Porokhonskyy, V.; Pashkin, A.; Franke, I.; Roleder, K.; Suchanicz, J.; Klein, R.; et al. Infrared, Raman and high-frequency dielectric spectroscopy and the phase transitions in $\mathrm{Na}_{1 / 2} \mathrm{Bi}_{1 / 2} \mathrm{TiO}_{3}$. J. Phys. Condens. Matter 2004, 16, 2719-2731. [CrossRef]

54. Hiruma, Y.; Nagata, H.; Takenaka, T. Thermal depoling process and piezoelectric properties of bismuth sodium titanate ceramics. J. Appl. Phys. 2009, 105, 084112. [CrossRef] 
55. Pronin, I.P.; Syrnikov, P.P.; Isupov, V.A.; Egorov, V.M.; Zaitseva, N.V. Peculiarities of phase transitions in sodium-bismuth titanate. Ferroelectrics 1980, 25, 395-397. [CrossRef]

56. Kruzina, T.; Duda, V.; Suchanicz, J. Peculiarities of optical behaviour of $\mathrm{Na}_{0.5} \mathrm{Bi}_{0.5} \mathrm{TiO}_{3}$ single crystals. Mater. Sci. Eng. B 2001, 87, 48-52. [CrossRef]

57. Sakata, K.; Masuda, Y. Ferroelectric and antiferroelectric properties of $\left(\mathrm{Na}_{0.5} \mathrm{Bi}_{0.5}\right) \mathrm{TiO}_{3}-\mathrm{SrTiO}_{3}$ solid solution ceramics. Ferroelectrics 1974, 7, 347-349. [CrossRef]

58. Vakhrushev, S.; Okuneva, N.; Plachenova, É.; Syrnikov, P. Phase transitions in sodium-bismuth titanate. JETP Lett. 1982, 35, 134-137.

59. Vakhrushev, S.; Isupov, V.; Kvyatkovsky, B.; Okuneva, N.; Pronin, I.; Smolensky, G.; Syrnikov, P. Phase transitions and soft modes in sodium bismuth titanate. Ferroelectrics 1985, 63, 153-160. [CrossRef]

60. Zhang, M.-S.; Scott, J.; Zvirgzds, J. Raman spectroscopy of $\mathrm{Na}_{0.5} \mathrm{Bi}_{0.5} \mathrm{TiO}_{3}$. Ferroelectr. Lett. Sect. 1986, 6, 147-152. [CrossRef]

61. Suchanicz, J.; Roleder, K.; Kania, A.; Hańaderek, J. Electrostrictive strain and pyroeffect in the region of phase coexistence in $\mathrm{Na}_{0.5} \mathrm{Bi}_{0.5} \mathrm{TiO}_{3}$. Ferroelectrics 1988, 77, 107-110. [CrossRef]

62. Suchanicz, J.; Ptak, W.S. On the phase transition in $\mathrm{Na}_{0.5} \mathrm{Bi}_{0.5} \mathrm{TiO}_{3}$. Ferroelectr. Lett. Sect. 1990, 12, 71-78. [CrossRef]

63. Suchanicz, J.; Kwapulinski, J. X-ray diffraction study of the phase transitions in $\mathrm{Na}_{0.5} \mathrm{Bi}_{0.5} \mathrm{TiO}_{3}$. Ferroelectrics 1995, 165, 249-253. [CrossRef]

64. Suchanicz, J. Investigations of the phase transitions in $\mathrm{Na}_{0.5} \mathrm{Bi}_{0.5} \mathrm{TiO}_{3}$. Ferroelectrics 1995, 172, $455-458$. [CrossRef]

65. Suchanicz, J. Peculiarities of phase transitions in $\mathrm{Na}_{0.5} \mathrm{Bi}_{0.5} \mathrm{TiO}_{3}$. Ferroelectrics 1997, 190, 77-81. [CrossRef]

66. Jones, G.O.; Kreisel, J.; Jennings, V.; Geday, M.A.; Thomas, P.A.; Glazer, A.M. Investigation of a peculiar relaxor ferroelectric: $\mathrm{Na}_{0.5} \mathrm{Bi}_{0.5} \mathrm{TiO}_{3}$. Ferroelectrics 2002, 270, 191-196. [CrossRef]

67. Li, M.; Li, L.; Zang, J.; Sinclair, D.C. Donor-doping and reduced leakage current in Nb-doped $\mathrm{Na}_{0.5} \mathrm{Bi}_{0.5} \mathrm{TiO}_{3}$. Appl. Phys. Lett. 2015, 106, 102904. [CrossRef]

68. Dorcet, V.; Trolliard, G.; Boullay, P. Reinvestigation of phase transitions in $\mathrm{Na}_{0.5} \mathrm{Bi}_{0.5} \mathrm{TiO}_{3}$ by TEM. Part I: First order rhombohedral to orthorhombic phase transition. Chem. Mater. 2008, 20, 5061-5073. [CrossRef]

69. Trolliard, G.; Dorcet, V. Reinvestigation of phase transitions in $\mathrm{Na}_{0.5} \mathrm{Bi}_{0.5} \mathrm{TiO}_{3}$ by TEM. Part II: Second order orthorhombic to tetragonal phase transition. Chem. Mater. 2008, 20, 5074-5082. [CrossRef]

70. Dorcet, V.; Trolliard, G.; Boullay, P. The structural origin of the antiferroelectric properties and relaxor behavior of $\mathrm{Na}_{0.5} \mathrm{Bi}_{0.5} \mathrm{TiO}_{3}$. J. Magn. Magn. Mater. 2009, 321, 1758-1761. [CrossRef]

71. Jaffe, B.; Cook, W.R.; Jaffe, H. Piezoelectric Ceramics; Academic Press Inc.: London, UK, 1971.

72. Takenaka, T.; Maruyama, K.-I.; Sakata, K. $\left(\mathrm{Bi}_{1 / 2} \mathrm{Na}_{1 / 2}\right) \mathrm{TiO}_{3}-\mathrm{BaTiO}_{3}$ system for lead-free piezoelectric ceramics. Jpn. J. Appl. Phys. Part 1 1991, 30, 2236-2239. [CrossRef]

73. Sasaki, A.; Chiba, T.; Mamiya, Y.; Otsuki, E. Dielectric and piezoelectric properties of $\left(\mathrm{Bi}_{0.5} \mathrm{Na}_{0.5}\right) \mathrm{TiO}_{3}-\left(\mathrm{Bi}_{0.5} \mathrm{~K}_{0.5}\right) \mathrm{TiO}_{3}$ systems. Jpn. J. Appl. Phys. Part 1 1999, 38, 5564-5567. [CrossRef]

74. Chu, B.J.; Chen, D.R.; Li, G.R.; Yin, Q.R. Electrical properties of $\mathrm{Na}_{1 / 2} \mathrm{Bi}_{1 / 2} \mathrm{TiO}_{3}-\mathrm{BaTiO}_{3}$ ceramics. J. Eur. Ceram. Soc. 2002, 22, 2115-2121. [CrossRef]

75. Wang, X.X.; Tang, X.G.; Chan, H.L.W. Electromechanical and ferroelectric properties of $\left(\mathrm{Bi}_{1 / 2} \mathrm{~K}_{1 / 2}\right) \mathrm{TiO}_{3}-\left(\mathrm{Bi}_{1 / 2} \mathrm{Na}_{1 / 2}\right) \mathrm{TiO}_{3}-\mathrm{BaTiO}_{3}$ lead-free piezoelectric ceramics. Appl. Phys. Lett. 2004, 85, 91-93. [CrossRef]

76. Isupov, V.A. Ferroelectric $\mathrm{Na}_{0.5} \mathrm{Bi}_{0.5} \mathrm{TiO}_{3}$ and $\mathrm{K}_{0.5} \mathrm{Bi}_{0.5} \mathrm{TiO}_{3}$ perovskites and their solid solutions. Ferroelectrics 2005, 315, 123-147. [CrossRef]

77. Zhang, S.-T.; Kounga, A.B.; Aulbach, E.; Ehrenberg, H.; Roedel, J. Giant strain in lead-free piezoceramics $\mathrm{Na}_{0.5} \mathrm{Bi}_{0.5} \mathrm{TiO}_{3}-\mathrm{BaTiO}_{3}-\mathrm{K}_{0.5} \mathrm{Na}_{0.5} \mathrm{NbO}_{3}$ system. Appl. Phys. Lett. 2007, 91, 112906. [CrossRef]

78. Jo, W.; Granzow, T.; Aulbach, E.; Rödel, J.; Damjanovic, D. Origin of the large strain response in $\left(\mathrm{K}_{0.5} \mathrm{Na}_{0.5}\right) \mathrm{NbO}_{3}$-modified $\left(\mathrm{Bi}_{0.5} \mathrm{Na}_{0.5}\right) \mathrm{TiO}_{3}-\mathrm{BaTiO}_{3}$ lead-free piezoceramics. J. Appl. Phys. 2009, 105, 094102. [CrossRef]

79. Guo, Y.; Liu, Y.; Withers, R.L.; Brink, F.; Chen, H. Large electric field-induced strain and antiferroelectric behavior in $(1-x)\left(\mathrm{Na}_{0.5} \mathrm{Bi}_{0.5}\right) \mathrm{TiO}_{3}-x \mathrm{BaTiO}_{3}$ ceramics. Chem. Mater. 2011, 23, 219-228. [CrossRef]

80. Jo, W.; Daniels, J.E.; Jones, J.L.; Tan, X.; Thomas, P.A.; Damjanovic, D.; Roedel, J. Evolving morphotropic phase boundary in lead-free $\left(\mathrm{Bi}_{1 / 2} \mathrm{Na}_{1 / 2}\right) \mathrm{TiO}_{3}-\mathrm{BaTiO}_{3}$ piezoceramics. J. Appl. Phys. 2011, 109, 014110. [CrossRef] 
81. Jo, W.; Schaab, S.; Sapper, E.; Schmitt, L.A.; Kleebe, H.-J.; Bell, A.J.; Roedel, J. On the phase identity and its thermal evolution of lead free $\left(\mathrm{Bi}_{1 / 2} \mathrm{Na}_{1 / 2}\right) \mathrm{TiO}_{3}-6 \mathrm{~mol} \% \mathrm{BaTiO}_{3}$. J. Appl. Phys. 2011, 110, 074106. [CrossRef]

82. Wylie-van Eerd, B.; Damjanovic, D.; Klein, N.; Setter, N.; Trodahl, J. Structural complexity of $\left(\mathrm{Na}_{0.5} \mathrm{Bi}_{0.5}\right) \mathrm{TiO}_{3}-\mathrm{BaTiO}_{3}$ as revealed by Raman spectroscopy. Phys. Rev. B 2010, 82, 104112. [CrossRef]

83. Ma, C.; Tan, X. Phase diagram of unpoled lead-free $(1-x)\left(\mathrm{Bi}_{1 / 2} \mathrm{Na}_{1 / 2}\right) \mathrm{TiO}_{3}-x \mathrm{BaTiO}_{3}$ ceramics. Solid State Commun. 2010, 150, 1497-1500. [CrossRef]

84. Anton, E.-M.; Schmitt, L.A.; Hinterstein, M.; Trodahl, J.; Kowalski, B.; Jo, W.; Kleebe, H.-J.; Rödel, J.; Jones, J.L. Structure and temperature-dependent phase transitions of lead-free $\mathrm{Bi}_{1 / 2} \mathrm{Na}_{1 / 2} \mathrm{TiO}_{3}-\mathrm{Bi}_{1 / 2}$ $\mathrm{K}_{1 / 2} \mathrm{TiO}_{3}-\mathrm{K}_{0.5} \mathrm{Na}_{0.5} \mathrm{NbO}_{3}$ piezoceramics. J. Mater. Res. 2012, 27, 2466-2478. [CrossRef]

85. Dittmer, R.; Anton, E.-M.; Jo, W.; Simons, H.; Daniels, J.E.; Hoffman, M.; Pokorny, J.; Reaney, I.M.; Rödel, J. A high-temperature-capacitor dielectric based on $\mathrm{K}_{0.5} \mathrm{Na}_{0.5} \mathrm{NbO}_{3}$-modified $\mathrm{Bi}_{1 / 2} \mathrm{Na}_{1 / 2} \mathrm{TiO}_{3}-\mathrm{Bi}_{1 / 2} \mathrm{~K}_{1 / 2} \mathrm{TiO}_{3}$. J. Am. Ceram. Soc. 2012, 95, 3519-3524. [CrossRef]

86. Zang, J.; Li, M.; Sinclair, D.C.; Frömling, T.; Jo, W.; Rödel, J. Impedance spectroscopy of $\left(\mathrm{Bi}_{1 / 2} \mathrm{Na}_{1 / 2}\right) \mathrm{TiO}_{3}-\mathrm{BaTiO}_{3}$ based high-temperature dielectrics. J. Am. Ceram. Soc. 2014, 97, 2825-2831. [CrossRef]

87. Zang, J.; Li, M.; Sinclair, D.C.; Jo, W.; Rödel, J. Impedance spectroscopy of $\left(\mathrm{Bi}_{1 / 2} \mathrm{Na}_{1 / 2}\right) \mathrm{TiO}_{3}-\mathrm{BaTiO}_{3}$ ceramics modified with $\left(\mathrm{K}_{0.5} \mathrm{Na}_{0.5}\right) \mathrm{NbO}_{3}$. J. Am. Ceram. Soc. 2014, 97, 1523-1529. [CrossRef]

88. Nagata, H.; Yoshida, M.; Makiuchi, Y.; Takenaka, T. Large piezoelectric constant and high Curie temperature of lead-free piezoelectric ceramic ternary system based on bismuth sodium titanate-bismuth potassium titanate-barium titanate near the morphotropic phase boundary. Jpn. J. Appl. Phys. Part 1 2003, 42, 7401-7403. [CrossRef]

89. Zhang, S.-T.; Yan, F.; Yang, B.; Cao, W. Phase diagram and electrostrictive properties of $\mathrm{Bi}_{0.5} \mathrm{Na}_{0.5} \mathrm{TiO}_{3}-\mathrm{BaTiO}_{3}-\mathrm{K}_{0.5} \mathrm{Na}_{0.5} \mathrm{NbO}_{3}$ ceramics. Appl. Phys. Lett. 2010, 97, 122901. [CrossRef]

90. Gröting, M.; Albe, K. Theoretical prediction of morphotropic compositions in $\mathrm{Na}_{1 / 2} \mathrm{Bi}_{1 / 2} \mathrm{TiO}_{3}$-based solid solutions from transition pressures. Phys. Rev. B 2014, 89, 054105. [CrossRef]

91. Ma, C.; Guo, H.; Beckman, S.P.; Tan, X. Creation and destruction of morphotropic phase boundaries through electrical poling: A case study of lead-free $\left(\mathrm{Bi}_{1 / 2} \mathrm{Na}_{1 / 2}\right) \mathrm{TiO}_{3}-\mathrm{BaTiO}_{3}$ piezoelectrics. Phys. Rev. Lett. 2012, 109, 107602. [CrossRef] [PubMed]

92. Elkechai, O.; Manier, M.; Mercurio, J.P. $\mathrm{Na}_{0.5} \mathrm{Bi}_{0.5} \mathrm{TiO}_{3}-\mathrm{K}_{0.5} \mathrm{Bi}_{0.5} \mathrm{TiO}_{3}(\mathrm{NBT}-\mathrm{KBT})$ system: A structural and electrical study. Phys. Status Solidi A 1996, 157, 499-506. [CrossRef]

93. Jones, G.O.; Kreisel, J.; Thomas, P.A. A structural study of the $\left(\mathrm{Na}_{1-x} \mathrm{~K}_{\mathrm{x}}\right)_{0.5} \mathrm{Bi}_{0.5} \mathrm{TiO}_{3}$ perovskite series as a function of substitution $(x)$ and temperature. Powder Diffr. 2002, 17, 301-319. [CrossRef]

94. Xie, H.; Jin, L.; Shen, D.; Wang, X.; Shen, G. Morphotropic phase boundary, segregation effect and crystal growth in the NBT-KBT system. J. Cryst. Growth 2009, 311, 3626-3630. [CrossRef]

95. Zuo, R.Z.; Su, S.; Wu, Y.; Fu, J.; Wang, M.; Li, L.T. Influence of A-site nonstoichiometry on sintering, microstructure and electrical properties of $\left(\mathrm{Bi}_{0.5} \mathrm{Na}_{0.5}\right) \mathrm{TiO}_{3}$ ceramics. Mater. Chem. Phys. 2008, 110, 311-315. [CrossRef]

96. Sung, Y.S.; Kim, J.M.; Cho, J.H.; Song, T.K.; Kim, M.H.; Chong, H.H.; Park, T.G.; Do, D.; Kim, S.S. Effects of Na nonstoichiometry in $\mathrm{Bi}_{0.5} \mathrm{Na}_{(0.5+x)} \mathrm{TiO}_{3}$ ceramics. Appl. Phys. Lett. 2010, 96, 022901. [CrossRef]

97. Sung, Y.S.; Kim, J.M.; Cho, J.H.; Song, T.K.; Kim, M.H.; Park, T.G. Effects of Bi nonstoichiometry in $\mathrm{Bi}_{(0.5+x)} \mathrm{Na}_{0.5} \mathrm{TiO}_{3}$ ceramics. Appl. Phys. Lett. 2011, 98, 012902. [CrossRef]

98. Jeong, I.-K.; Sung, Y.; Song, T.; Kim, M.-H.; Llobet, A. Structural evolution of bismuth sodium titanate induced by A-site non-stoichiometry: Neutron powder diffraction studies. J. Korean Phys. Soc. 2015, 9. [CrossRef]

99. Carter, J.; Aksel, E.; Iamsasri, T.; Forrester, J.S.; Chen, J.; Jones, J.L. Structure and ferroelectricity of nonstoichiometric $\left(\mathrm{Na}_{0.5} \mathrm{Bi}_{0.5}\right) \mathrm{TiO}_{3}$. Appl. Phys. Lett. 2014, 104, 112904. [CrossRef]

100. Naderer, M.; Kainz, T.; Schütz, D.; Reichmann, K. The influence of Ti-nonstoichiometry in $\mathrm{Bi}_{0.5} \mathrm{Na}_{0.5} \mathrm{TiO}_{3}$. J. Eur. Ceram. Soc. 2014, 34, 663-667. [CrossRef]

101. Spreitzer, M.; Valant, M.; Suvorov, D. Sodium deficiency in $\mathrm{Na}_{0.5} \mathrm{Bi}_{0.5} \mathrm{TiO}_{3}$. J. Mater. Chem. 2007, 17, $185-192$. [CrossRef]

102. Li, M.; Pietrowski, M.J.; de Souza, R.A.; Zhang, H.; Reaney, I.M.; Cook, S.N.; Kilner, J.A.; Sinclair, D.C. A family of oxide ion conductors based on the ferroelectric perovskite $\mathrm{Na}_{0.5} \mathrm{Bi}_{0.5} \mathrm{TiO}_{3}$. Nat. Mater. 2014, 13, 31-35. [CrossRef] [PubMed] 
103. Li, M.; Zhang, H.; Cook, S.N.; Li, L.; Kilner, J.A.; Reaney, I.M.; Sinclair, D.C. Dramatic influence of A-site nonstoichiometry on the electrical conductivity and conduction mechanisms in the perovskite oxide $\mathrm{Na}_{0.5} \mathrm{Bi}_{0.5} \mathrm{TiO}_{3}$. Chem. Mater. 2015, 27, 629-634. [CrossRef]

104. Smyth, D.M. The Defect Chemistry of Metal Oxides; Oxford University Press: New York, NY, USA, 2000.

105. Bousquet, M.; Duclere, J.R.; Orhan, E.; Boulle, A.; Bachelet, C.; Champeaux, C. Optical properties of an epitaxial $\mathrm{Na}_{0.5} \mathrm{Bi}_{0.5} \mathrm{TiO}_{3}$ thin film grown by laser ablation: Experimental approach and density functional theory calculations. J. Appl. Phys. 2010, 107, 104107. [CrossRef]

106. Kim, C.Y.; Sekino, T.; Niihara, K. Optical, mechanical, and dielectric properties of $\mathrm{Bi}_{1 / 2} \mathrm{Na}_{1 / 2} \mathrm{TiO}_{3}$ thin film synthesized by sol-gel method. J. Sol-Gel Sci. Technol. 2010, 55, 306-310. [CrossRef]

107. Zeng, M.; Or, S.W.; Chan, H.L.W. First-principles study on the electronic and optical properties of $\mathrm{Na}_{0.5} \mathrm{Bi}_{0.5} \mathrm{TiO}_{3}$ lead-free piezoelectric crystal. J. Appl. Phys. 2010, 107, 043513. [CrossRef]

108. Schütz, D.; Deluca, M.; Krauss, W.; Feteira, A.; Jackson, T.; Reichmann, K. Lone-pair-induced covalency as the cause of temperature- and field-induced instabilities in bismuth sodium titanate. Adv. Funct. Mater. 2012, 22, 2285-2294. [CrossRef]

109. Krauss, W.; Schütz, D.; Mautner, F.A.; Feteira, A.; Reichmann, K. Piezoelectric properties and phase transition temperatures of the solid solution of $(1-x)\left(\mathrm{Bi}_{0.5} \mathrm{Na}_{0.5}\right) \mathrm{TiO}_{3}-x \mathrm{SrTiO}_{3}$. J. Eur. Ceram. Soc. 2010, 30, 1827-1832. [CrossRef]

110. Jo, W.; Dittmer, R.; Acosta, M.; Zang, J.; Groh, C.; Sapper, E.; Wang, K.; Rödel, J. Giant electric-field-induced strains in lead-free ceramics for actuator applications-Status and perspective. J. Electroceram. 2012, 29, 71-93. [CrossRef]

111. Takenaka, T.; Nagata, H.; Hiruma, Y. Phase-transition temperatures and piezoelectric properties of $\left(\mathrm{Bi}_{1 / 2} \mathrm{Na}_{1 / 2}\right) \mathrm{TiO}_{3}$ and $\left(\mathrm{Bi}_{1 / 2} \mathrm{~K}_{1 / 2}\right) \mathrm{TiO}_{3}$-based bismuth perovskite lead-free ferroelectric ceramics. IEEE TUFFC 2009, 56, 1595-1612. [CrossRef] [PubMed]

112. Watanabe, Y.; Hiruma, Y.; Nagata, H.; Takenaka, T. Phase transition temperature and electrical properties of divalent ions $\left(\mathrm{Ca}^{2+}, \mathrm{Sr}^{2+}\right.$ and $\left.\mathrm{Ba}^{2+}\right)$ substituted $\left(\mathrm{Bi}_{1 / 2} \mathrm{Na}_{1 / 2}\right) \mathrm{TiO}_{3}$ ceramics. Ceram. Int. 2008, 34, 761-764. [CrossRef]

113. Zhang, S.; Kounga, A.; Aulbach, E. Giant strain in lead-free piezoceramics $\mathrm{Bi}_{0.5} \mathrm{Na}_{0.5} \mathrm{TiO}_{3}-\mathrm{BaTiO}_{3}-\mathrm{K}_{0.5} \mathrm{Na}_{0.5} \mathrm{NbO}_{3}$ system. Appl. Phys. Lett. 2007, 91, 112906. [CrossRef]

114. Chiang, Y.M.; Farrey, G.W.; Soukhojak, A.N. Lead-free high-strain single-crystal piezoelectrics in the alkaline-bismuth-titanate perovskite family. Appl. Phys. Lett. 1998, 73, 3683-3685. [CrossRef]

115. Tani, T. Crystalline-oriented piezoelectric bulk ceramics with a perovskite-type structure. J. Korean Phys. Soc. 1998, 32, S1217-S1220.

116. Kimura, T. Application of texture engineering to piezoelectric ceramics-A review. J. Ceram. Soc. Jpn. 2006, 114, 15-25. [CrossRef]

117. Messing, G.L.; Trolier-McKinstry, S.; Sabolsky, E.M.; Duran, C.; Kwon, S.; Brahmaroutu, B.; Park, P.; Yilmaz, H.; Rehrig, P.W.; Eitel, K.B.; et al. Templated grain growth of textured piezoelectric ceramics. Crit. Rev. Solid State Mater. Sci. 2004, 29, 45-96. [CrossRef]

118. Yilmaz, H.; Messing, G.L.; Trolier-McKinstry, S. Textured sodium bismuth titanate $\left(\mathrm{Na}_{1 / 2} \mathrm{Bi}_{1 / 2}\right)_{0.945} \mathrm{Ba}_{0.055} \mathrm{TiO}_{3}$ ceramics by templated grain growth. In Proceedings of the 2000 12th IEEE International Symposium on Applications of Ferroelectrics, Honolulu, HI, USA, 21 July-2 August 2000; pp. 405-408.

119. Yilmaz, H.; Trolier-McKinstry, S.; Messing, G.L. (Reactive) templated grain growth of textured sodium bismuth titanate $\left(\mathrm{Na}_{1 / 2} \mathrm{Bi}_{1 / 2} \mathrm{TiO}_{3}-\mathrm{BaTiO}_{3}\right)$ ceramics-II dielectric and piezoelectric properties. J. Electroceram. 2003, 11, 217-226. [CrossRef]

120. Fukuchi, E.; Kimura, T.; Tani, T.; Takeuch, T.; Saito, Y. Effect of potassium concentration on the grain orientation in bismuth sodium potassium titanate. J. Am. Ceram. Soc. 2002, 85, 1461-1466. [CrossRef]

121. West, D.L.; Payne, D.A. Microstructure development in reactive-templated grain growth of $\mathrm{Bi}_{1 / 2} \mathrm{Na}_{1 / 2} \mathrm{TiO}_{3}$-based ceramics: Template and formulation effects. J. Am. Ceram. Soc. 2003, 86, 769-774. [CrossRef]

122. Kimura, T.; Takahashi, T.; Tani, T.; Saito, Y. Crystallographic texture development in bismuth sodium titanate prepared by reactive-templated grain growth method. J. Am. Ceram. Soc. 2004, 87, 1424-1429. [CrossRef] 
123. Kimura, T.; Takahashi, T.; Tani, T.; Saito, Y. Preparation of crystallographically textured $\mathrm{Bi}_{0.5} \mathrm{Na}_{0.5} \mathrm{TiO}_{3}-\mathrm{BaTiO}_{3}$ ceramics by reactive-templated grain growth method. Ceram. Int. 2004, 30, 1161-1167. [CrossRef]

124. Fuse, K.; Kimura, T. Effect of particle sizes of starting materials on microstructure development in textured $\mathrm{Bi}_{0.5}\left(\mathrm{Na}_{0.5} \mathrm{~K}_{0.5}\right)_{0.5} \mathrm{TiO}_{3}$. J. Am. Ceram. Soc. 2006, 89, 1957-1964. [CrossRef]

125. Zeng, J.T.; Kwok, K.W.; Tam, W.K.; Tian, H.Y.; Jiang, X.P.; Chan, H.L.W. Plate-like $\mathrm{Na}_{0.5} \mathrm{Bi}_{0.5} \mathrm{TiO}_{3}$ template synthesized by a topochemical method. J. Am. Ceram. Soc. 2006, 89, 3850-3853. [CrossRef]

126. Zhao, W.; Ya, J.; Xin, Y.; Lie, E.; Zhao, D.; Zhou, H. Fabrication of $\mathrm{Na}_{0.5} \mathrm{Bi}_{0.5} \mathrm{TiO}_{3}-\mathrm{BaTiO}_{3}-\mathrm{Textured}$ ceramics templated by plate-like $\mathrm{Na}_{0.5} \mathrm{Bi}_{0.5} \mathrm{TiO}_{3}$ particles. J. Am. Ceram. Soc. 2009, 92, 1607-1609. [CrossRef]

127. Zhao, W.; Zhou, H.; Yan, Y.; Liu, D. Topochemical synthesis of plate-like $\mathrm{Na}_{0.5} \mathrm{Bi}_{0.5} \mathrm{TiO}_{3}$ from Aurivillius precursor. J. Am. Ceram. Soc. 2008, 91, 1322-1325. [CrossRef]

128. Gao, F.; Hong, R.-Z.; Liu, J.-J.; Yao, Y.-H.; Tian, C.-S. Effect of different templates on microstructure of textured $\mathrm{Na}_{0.5} \mathrm{Bi}_{0.5} \mathrm{TiO}_{3}-\mathrm{BaTiO}_{3}$ ceramics with RTGG method. J. Eur. Ceram. Soc. 2008, 28, 2063-2070. [CrossRef]

129. Maurya, D.; Murayama, M.; Priya, S. Synthesis and characterization of $\mathrm{Na}_{2} \mathrm{Ti}_{6} \mathrm{O}_{13}$ whiskers and their transformation to $(1-x) \mathrm{Na}_{0.5} \mathrm{Bi}_{0.5} \mathrm{TiO}_{3}-\mathrm{xBaTiO}_{3}$ ceramics. J. Am. Ceram. Soc. 2011, 94, 2857-2871. [CrossRef]

130. Maurya, D.; Zhou, Y.; Yan, Y.; Priya, S. Synthesis mechanism of grain-oriented lead-free piezoelectric $\mathrm{Na}_{0.5} \mathrm{Bi}_{0.5} \mathrm{TiO}_{3}-\mathrm{BaTiO}_{3}$ ceramics with giant piezoelectric response. J. Mater. Chem. C 2013, 1, 2102-2111.

131. Maurya, D.; Zhou, Y.; Wang, Y.; Yan, Y.; Li, J.; Viehland, D.; Priya, S. Giant strain with ultra-low hysteresis and high temperature stability in grain oriented lead-free $\mathrm{K}_{0.5} \mathrm{Bi}_{0.5} \mathrm{TiO}_{3}-\mathrm{BaTiO}_{3}-\mathrm{Na}_{0.5} \mathrm{Bi}_{0.5} \mathrm{TiO}_{3}$ piezoelectric materials. Sci. Rep. 2015, 5. [CrossRef] [PubMed]

132. Hu, D.; Mori, K.; Kong, X.; Shinagawa, K.; Wada, S.; Feng, Q. Fabrication of [100] -oriented bismuth sodium titanate ceramics with small grain size and high density for piezoelectric materials. J. Eur. Ceram. Soc. 2014, 34, 1169-1180. [CrossRef]

133. Hussain, A.; Maqbool, A.; Malik, R.A.; Rahman, J.U.; Song, T.-K.; Kim, W.-J.; Kim, M.-H. $\mathrm{Na}_{0.5} \mathrm{Bi}_{0.5} \mathrm{TiO}_{3}-\mathrm{BaZrO} 3$ textured ceramics prepared by reactive templated grain growth method. Ceram. Int. 2015, 41, S26-S30. [CrossRef]

134. Zhang, H.; Xu, P.; Patterson, E.; Zang, J.; Jiang, S.; Roedel, J. Preparation and enhanced electrical properties of grain-oriented $\left(\mathrm{Bi}_{1 / 2} \mathrm{Na}_{1 / 2}\right) \mathrm{TiO}_{3}$-based lead-free incipient piezoceramics. J. Eur. Ceram. Soc. 2015, 35, 2501-2512. [CrossRef]

135. Randall, C.; Kelnberger, A.; Yang, G.; Eitel, R.; Shrout, T. High strain piezoelectric multilayer actuators-A material science and engineering challenge. J. Electroceram. 2005, 14, 177-191. [CrossRef]

136. Juuti, J.; Leinonen, M.; Jantunen, H. Micropositioning. In Piezoelectric and Acoustic Materials for Transducer Applications; Safari, A., Akdogan, E.K., Eds.; Springer Science + Business Media: New York, NY, USA, 2008.

137. Lucato, S.; Lupascu, D.C.; Kamlah, M.; Rödel, J.; Lynch, C.S. Constraint-induced crack initiation at electrode edges in piezoelectric ceramics. Acta Mater. 2001, 49, 2751-2759. [CrossRef]

138. Koch, J. Piezoxide (PXE)—Eigenschaften und Anwendungen; Dr. Alfred Hüthig Verlag GmbH: Heidelberg, Germany, 1988.

139. Dittmer, R.; Aulbach, E.; Jo, W.; Webber, K.G.; Rödel, J. Large blocking force in $\mathrm{Bi}_{1 / 2} \mathrm{Na}_{1 / 2} \mathrm{TiO}_{3}$-based lead-free piezoceramics. Scr. Mater. 2012, 67, 100-103. [CrossRef]

140. Reichmann, K.; Deluca, M.; Schütz, D.; Supancic, P. Load characteristics of lead-free ceramic multilayer actuators based on bismuth-sodium-titanate. Int. J. Appl. Ceram. Technol. 2014, 11, 431-435. [CrossRef]

141. Krauss, W.; Schütz, D.; Naderer, M.; Orosel, D.; Reichmann, K. BNT-based multilayer device with large and temperature independent strain made by a water-based preparation process. J. Eur. Ceram. Soc. 2011, 31, 1857-1860. [CrossRef]

142. Zuo, R.; Ye, C.; Fang, X.; Li, J. Tantalum doped 0.94Bi ${ }_{0.5} \mathrm{Na}_{0.5} \mathrm{TiO}_{3}-0.06 \mathrm{BaTiO}_{3}$ piezoelectric ceramics. J. Eur. Ceram. Soc. 2008, 28, 871-877. [CrossRef]

143. Yang, Z.; Liu, B.; Wei, L.; Hou, Y. Structure and electrical properties of $(1-x) \mathrm{Bi}_{0.5} \mathrm{Na}_{0.5} \mathrm{TiO}_{3}-x \mathrm{Bi}_{0.5} \mathrm{~K}_{0.5} \mathrm{TiO}_{3}$ ceramics near morphotropic phase boundary. Mat. Res. Bull. 2008, 43, 81-89. [CrossRef]

144. Lupascu, D.; Rödel, J. Fatigue in bulk lead zirconate titanate actuator materials. Adv. Eng. Mater. 2005, 7, 882-898. [CrossRef] 
145. Glaum, J.; Hoffman, M. Electric fatigue of lead-free piezoelectric materials. J. Am. Ceram. Soc. 2014, 97, 665-680. [CrossRef]

146. Genenko, Y.A.; Glaum, J.; Hoffmann, M.J.; Albe, K. Mechanisms of aging and fatigue in ferroelectrics. Mater. Sci. Eng. B 2015, 192, 52-82. [CrossRef]

147. Luo, Z.; Glaum, J.; Granzow, T.; Jo, W.; Dittmer, R.; Hoffman, M.; Rödel, J. Bipolar and unipolar fatigue of ferroelectric BNT-based lead-free piezoceramics. J. Am. Ceram. Soc. 2011, 94, 529-535. [CrossRef]

148. Ehmke, M.; Glaum, J.; Jo, W.; Granzow, T.; Rödel, J. Stabilization of the fatigue-resistant phase by $\mathrm{CuO}$ addition in $\left(\mathrm{Bi}_{1 / 2} \mathrm{Na}_{1 / 2}\right) \mathrm{TiO}_{3}-\mathrm{BaTiO}_{3}$. J. Am. Ceram. Soc. 2011, 94, 2473-2478. [CrossRef]

149. Luo, Z.; Granzow, T.; Glaum, J.; Jo, W.; Rödel, J.; Hoffman, M. Effect of ferroelectric long-range order on the unipolar and bipolar electric fatigue in $\mathrm{Bi}_{1 / 2} \mathrm{Na}_{1 / 2} \mathrm{TiO}_{3}$-based lead-free piezoceramics. J. Am. Ceram. Soc. 2011, 94, 3927-3933. [CrossRef]

150. Sapper, E.; Gassmann, A.; Gjødvad, L.; Jo, W.; Granzow, T.; Rödel, J. Cycling stability of lead-free BNT-8BT and BNT-6BT-3KNN multilayer actuators and bulk ceramics. J. Eur. Ceram. Soc. 2014, 34, 653-661. [CrossRef]

151. Li, Y.; Wang, F.; Ye, X.; Xie, Y.; Tang, Y.; Sun, D.; Shi, W.; Zhao, X.; Luo, H. Large strain response and fatigue-resistant behavior in ternary $\mathrm{Bi}_{0.5} \mathrm{Na}_{0.5} \mathrm{TiO}_{3}-\mathrm{BaTiO}_{3}-\mathrm{Bi}\left(\mathrm{Zn}_{0.5} \mathrm{Ti}_{0.5}\right) \mathrm{O}_{3}$ solid solutions. J. Am. Ceram. Soc. 2014, 97, 3615-3623. [CrossRef]

152. Patterson, E.A.; Cann, D.P. Bipolar piezoelectric fatigue of $\mathrm{Bi}\left(\mathrm{Zn}_{0.5} \mathrm{Ti}_{0.5}\right) \mathrm{O}_{3}-\left(\mathrm{Bi}_{0.5} \mathrm{~K}_{0.5}\right) \mathrm{TiO}_{3}-\left(\mathrm{Bi}_{0.5} \mathrm{Na}_{0.5}\right) \mathrm{TiO}_{3}$ Pb-free ceramics. Appl. Phys. Lett. 2012, 101, 042905. [CrossRef]

153. Ueyama, R.; Kamada, K.; Harada, M.; Ueyama, T.; Yamamoto, T.; Kuribayashi, K. Low temperature synthesis of silver-palladium alloy powders internal electrodes for multilayer ceramic devices. J. Mater. Sci. 2001, 36, 371-379. [CrossRef]

154. Wang, S.F.; Huebner, W. Interaction of $\mathrm{Ag} / \mathrm{Pd}$ Metallization with lead and bismuth oxide-based fluxes in multilayer ceramic capacitors. J. Am. Ceram. Soc. 1992, 75, 2339-2352. [CrossRef]

155. Wang, S.F.; Huebner, W. Interaction of silver palladium electrodes with lead-based and bismuth-based electroceramics. J. Am. Ceram. Soc. 1993, 76, 474-480. [CrossRef]

156. Nagata, H.; Hiruma, Y.; Takenaka, T. Electric-field-induced strain for $\left(\mathrm{Bi}_{1 / 2} \mathrm{Na}_{1 / 2}\right) \mathrm{TiO}_{3}$-based lead-free multilayer actuator. J. Ceram. Soc. Jpn. 2010, 118, 726-730. [CrossRef]

157. Schuetz, D.; Krauss, W.; Albering, J.; Kurta, C.; Reichmann, K. The chemical interaction of silver-palladium alloy electrodes with bismuth-based piezomaterials. J. Am. Ceram. Soc. 2010, 93, 1142-1147. [CrossRef]

158. Nguyen, V.Q.; Kang, J.K.; Han, H.S.; Lee, H.Y.; Jeong, S.J.; Ahn, C.W.; Kim, I.W.; Lee, J.S. Bi-based lead-free ceramic multilayer actuators using AgPd- $\left(\mathrm{Na}_{0.51} \mathrm{~K}_{0.47} \mathrm{Li}_{0.02}\right)\left(\mathrm{Nb}_{0.8} \mathrm{Ta}_{0.2}\right) \mathrm{O}_{3}$ composite inner electrodes. Sens. Actuators A 2013, 200, 107-113. [CrossRef]

159. Ahn, C.W.; Kim, H.S.; Woo, W.S.; Won, S.S.; Seog, H.J.; Chae, S.A.; Park, B.C.; Jang, K.B.; Ok, Y.P.; Chong, H.H.; et al. Low temperature sintering of $\mathrm{Bi}_{0.5}(\mathrm{Na}, \mathrm{K})_{0.5} \mathrm{TiO}_{3}$ for multilayer ceramic actuators. J. Am. Ceram. Soc. 2015, 98, 1877-1883. [CrossRef]

(C) 2015 by the authors; licensee MDPI, Basel, Switzerland. This article is an open access article distributed under the terms and conditions of the Creative Commons by Attribution (CC-BY) license (http://creativecommons.org/licenses/by/4.0/). 